Research Paper

\title{
miR-146a suppresses 5-lipoxygenase activating protein (FLAP) expression and Leukotriene B4 production in lung cancer cells
}

\author{
Joseph R. Iacona ${ }^{1}$, Nicholas J. Monteleone ${ }^{1}$ and Carol S. Lutz ${ }^{1}$ \\ ${ }^{1}$ Department of Microbiology, Biochemistry and Molecular Genetics, Rutgers Biomedical and Health Sciences, New Jersey \\ Medical School and the School of Graduate Studies, Health Sciences Campus, Newark, NJ, USA \\ Correspondence to: Carol S. Lutz, email: lutzcs@njms.rutgers.edu \\ Keywords: lipoxygenase pathway; arachidonic acid; microRNA; gene expression; promoter methylation \\ Received: March 27, $2018 \quad$ Accepted: May 08, $2018 \quad$ Published: June 01, 2018 \\ Copyright: lacona et al. This is an open-access article distributed under the terms of the Creative Commons Attribution License \\ 3.0 (CC BY 3.0), which permits unrestricted use, distribution, and reproduction in any medium, provided the original author and \\ source are credited.
}

\section{ABSTRACT}

Arachidonic acid (AA) can be converted into prostaglandins (PGs) or leukotrienes (LTs) by the enzymatic actions of cyclooxygenases (COX-1 and COX-2) or 5-lipoxygenase (5-LO), respectively. PGs and LTs are lipid signaling molecules that have been implicated in various diseases, including multiple cancers. 5-LO and its activating protein (FLAP) work together in the first two conversion steps of LT production. Previous work has suggested a role for LTs in cancer development and progression. MicroRNAs (miRNAs) are small RNA molecules that negatively regulate gene expression post-transcriptionally, and have previously been shown to be involved in cancer. Here, we show that high FLAP expression is associated with lower overall survival in lung adenocarcinoma patients, and FLAP protein is overexpressed in lung cancer cells compared to normal lung cells. Our lab has previously shown that miR-146a regulates COX-2 in lung cancer cells, and this miRNA is also predicted to target FLAP. Transient and stable transfections of miR-146a repress endogenous FLAP expression in lung cancer cells, and reporter assays show this regulation occurs through a direct interaction between the FLAP $3^{\prime}$ untranslated region (UTR) and miR146a. Restoration of miR-146a also results in decreased cancer cell Leukotriene B4 $\left(\mathrm{LTB}_{4}\right)$ production. Additionally, methylation analysis indicates the miR-146a promoter is hypermethylated in lung cancer cell lines. Taken together, this study and previous work from our lab suggest miR-146a is an endogenous dual inhibitor of AA metabolism in lung cancer cells by regulating both PG and LT production through direct targeting of the COX-2 and FLAP 3' UTRs.

\section{INTRODUCTION}

Arachidonic acid (AA) metabolism and subsequent eicosanoid production is an important biochemical pathway that is more complex than is apparent at first glance. Eicosanoids are 20-carbon lipid molecules produced as a result of the enzymatic activities of cyclooxygenases (COX-1 and COX-2) and 5-lipoxygenase (5-LO/ALOX5). There are two main arms of the metabolic pathway: AA is converted by the actions of COX-1 and COX-2 into prostaglandins (PGs) and thromboxanes (TXs) in one arm and the actions of 5-LO and its associated protein, 5-Lipoxygenase Activating Protein (FLAP/ALOX5AP), create leukotrienes (LTs) in the other arm of the pathway [1-3]. FLAP is localized at the nuclear membrane, and is necessary for the cellular production of LTs by binding to AA and presenting it to 5-LO, which then converts AA into an intermediate that is later catalyzed into bioactive LTs [1,3]. AA metabolic enzymes are highly conserved in their amino acid sequence throughout mammalian evolution [4-6]. PGs, TXs, and LTs play roles in many homeostatic functions throughout the body, but also have pathophysiologic roles in cancer, inflammation, wound healing, asthma, allergic 
response, and bone fracture healing [7-15]. Thus, there is a need for meticulous regulation of these molecules.

COX-1 and COX-2 perform the same two enzymatic activities: oxidative cyclization and peroxidation of AA (2 and references therein). Our lab and others have demonstrated that COX-2 expression is regulated both transcriptionally and post-transcriptionally, including regulation by alternative polyadenylation of the COX-2 3' untranslated region (3' UTR) $[16,17]$ and microRNA (miRNA)-mediated regulation by several different miRNAs in multiple cell types and tissues [2, 18, 19]. Most notable for the purposes of the current study is the miR-146a-mediated suppression of COX-2 in lung cancer cells, as we have previously shown [19]. This regulation occurs through a direct and specific interaction between miR-146a and the COX-2 3' UTR.

FLAP works in concert with 5-LO in two consecutive reactions to convert AA to the intermediate Leukotriene A4 ( $\left.\mathrm{LTA}_{4}\right)$, which can be processed by a number of other enzymes into various LTs. LTs have long been studied in asthma and allergies, but recent evidence has implicated a role for them in cancer. Production of Leukotriene B4 $\left(\mathrm{LTB}_{4}\right)$, one of the most potent leukotrienes, is typically restricted to leukocytes, yet is synthesized in various diseased epithelial cells, including lung cancer cells [20-23]. $\mathrm{LTB}_{4}$ can stimulate cell proliferation and promote cell survival in both colon and pancreatic cancer cell lines, and in general supports a favorable microenvironment for tumor growth and metastasis [13, 24-26].

Although more is known about 5-LO gene expression mechanisms, regulation of FLAP is no less important. Aberrant regulation of these molecules has been implicated in cancer development and progression $[13,27]$. The pro-tumorigenic nature of LT metabolism has been demonstrated in numerous cancers, including but not limited to colorectal, lung, pancreatic, prostate, and chronic myeloid leukemia [28-32]. In addition, high FLAP expression in human breast cancer samples was correlated with decreased survival, and inhibiting FLAP activity attenuated breast tumor cell growth [33, 34]. Previous work has shown transcriptional activation to be key for regulation of FLAP [35-38], however, the role of post-transcriptional regulation has only recently been appreciated. The FLAP mRNA 3' UTR contains several computationally predicted miRNA binding sites. miR-335 and miR-199a-5p were described as direct regulators of FLAP expression in human brain endothelial cells [39]. Interestingly, the FLAP 3' UTR contains a predicted, highly conserved miR-146a binding site. We postulated that perhaps miR-146a might also regulate the other arm of the AA metabolic pathway, that is, the LT side in addition to the PG side. A single miRNA regulating both arms of a basic biochemical pathway would be an elegant and novel discovery.

Here, we demonstrate for the first time that FLAP is overexpressed in lung cancer. Cancer database analysis suggests a correlation between FLAP expression and overall survival in lung adenocarcinoma patients. This work also identifies FLAP as a novel target of miR$146 \mathrm{a}$, as this miRNA can downregulate FLAP expression through binding its 3' UTR. miR-146a treatment can also cause a significant decrease in $\mathrm{LTB}_{4}$ production. Finally, we show hypermethylation of the miR-146a promoter is responsible for its reduced expression in lung cancer cells. Taken together, these results highlight the discovery of miR-146a-mediated regulation of both arms of the AA metabolic pathway.

\section{RESULTS}

\section{High FLAP expression is negatively correlated with overall survival in lung adenocarcinoma patients}

In order to investigate the effect of FLAP expression in lung cancer patients, we utilized the Kaplan-Meier Plotter online tool (www.kmplot.com), a survival analysis software designed to identify cancer biomarkers with prognostic value based on patient transcriptomic data compiled from multiple studies. We consulted the version specific for non-small cell lung cancer (NSCLC) [40]. FLAP (ALOX5AP) gene expression was analyzed, and patients were categorized as having low or high expression based on how their FLAP level related to the median value.

Analysis of data from 1,926 NSCLC patients showed a trend of high FLAP expression correlating with a lower overall probability of survival, but this was not statistically significant $(P=0.15, \mathrm{HR}=1.1)$ (Figure 1A). 1,244 of these patients had an NSCLC subtype associated with their data. Upon subtype-specific analysis no significant difference in overall survival was seen in the 524 patients with lung squamous cell carcinoma $(P=0.34$, $\mathrm{HR}=0.89)($ Figure $1 \mathrm{~B})$. However, there was a highly significant correlation between high FLAP expression and lower overall probability of survival in the 720 patients with lung adenocarcinoma $\left(P=3.1 \times 10^{-7}, \mathrm{HR}=1.86\right)$ (Figure 1C). These data preliminarily suggest FLAP expression may be used as a prognostic biomarker in lung adenocarcinoma. Why these results are subtype-specific is unclear, and is an interesting point for future investigation.

\section{FLAP expression in lung cell lines}

Our laboratory and others have reported COX-2 overexpression in various cancer cells (19 and references therein). Increased 5-LO expression also has been demonstrated in various cancers [28-32]. However, the pro-cancer role of FLAP has only been focused on in detail in the context of breast cancer $[33,34]$. In order to establish FLAP protein levels in lung cell lines, Western blot analysis was performed on lysates from A549, H1299, 
and H1975 cells (lung adenocarcinoma) and compared to lysates from Beas2B cells (normal immortalized lung). As seen in Figure 2A, 2B, FLAP protein is significantly upregulated in A549 and H1299 cells compared to Beas2B cells, suggesting a potential role for FLAP in lung adenocarcinoma. FLAP protein is also upregulated in H1975 cells, but the data were not statistically significant.

In order to establish the relative abundance of FLAP mRNA in these lung cells, real-time quantitative reverse transcriptase PCR (qRT-PCR) was performed.
A
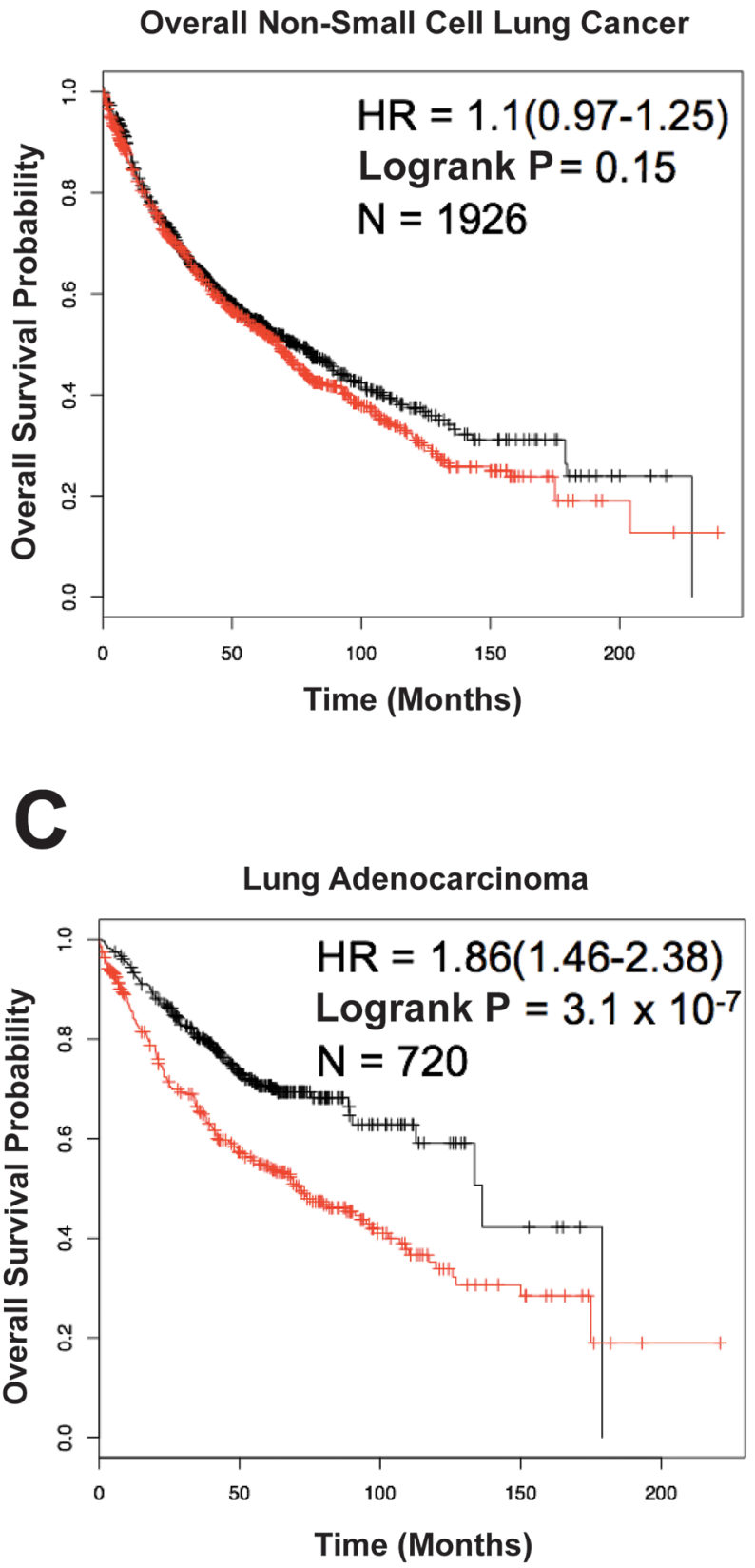

B

Lung Squamous Cell Carcinoma

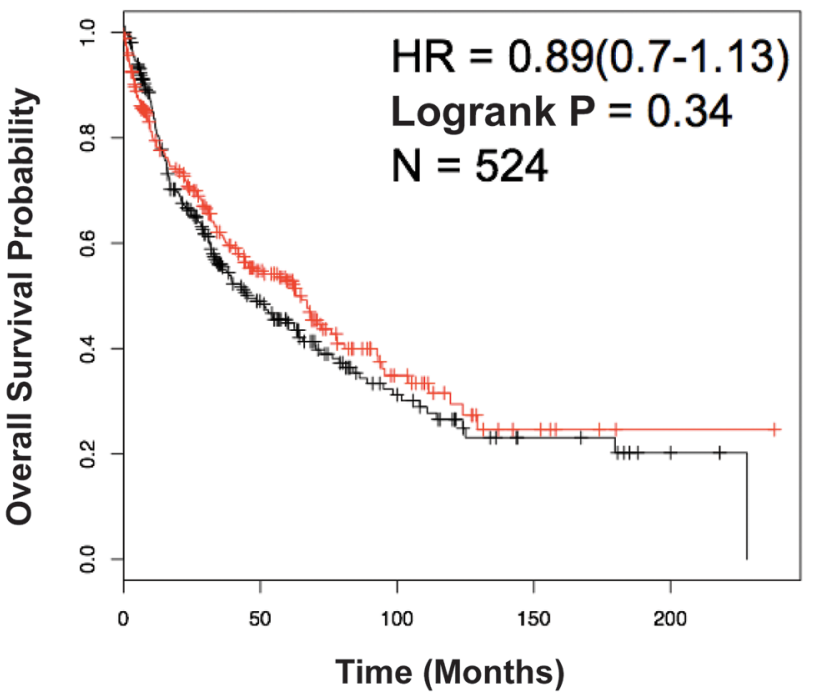

FLAP Expression

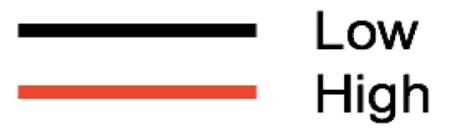

Figure 1: 5-Lipoxygenase Activating Protein (FLAP) expression may have prognostic value in lung adenocarcinoma. The Non-Small Cell Lung Cancer (NSCLC) KM Plotter Tool (http://www.kmplot.com) was used to generate survival curves based on a patient's overall survival in months and their FLAP expression level (low or high) relative to the median value. (A) No significant correlation between FLAP expression and overall survival in 1,926 NSCLC patients $(P=0.15)$. (B) No significant correlation between FLAP expression and overall survival in 524 lung squamous cell carcinoma patients $(P=0.34)$. (C) Highly significant correlation between FLAP expression and overall survival in 720 lung adenocarcinoma patients $\left(P=3.1 \times 10^{-7}\right)$. 
Comparative Cycle Threshold (CT) $(\Delta \Delta \mathrm{CT})$ data analysis revealed that Beas $2 \mathrm{~B}$ cells express significantly more FLAP mRNA than A549 and H1299 cells, but no significant difference was observed when compared to H1975 cells (Figure 2C). These findings are intriguing, since they show an inverse expression pattern between FLAP mRNA and protein (Figure 2B). Maier et al. analyzed the literature and determined that, in general, an overall poor correlation exists between mRNA and protein levels in various cell types and species. The authors propose multiple reasons for this: 1) post-transcriptional regulation, 2) post-translational regulation, and 3) background noise and experimental error [41]. Our data suggest post-transcriptional and/or translational regulation is occurring in the normal lung cells, leading to a lower relative level of FLAP protein despite a higher abundance of its mRNA. This regulation may be reduced or lost in the lung cancer cells, resulting in overexpression of FLAP protein.

\section{FLAP is a predicted target of miR-146a}

Multiple forms of post-transcriptional regulation may be at play resulting in this disparity between FLAP mRNA and protein expression. There are two predicted splice variants of FLAP, both of which have the same

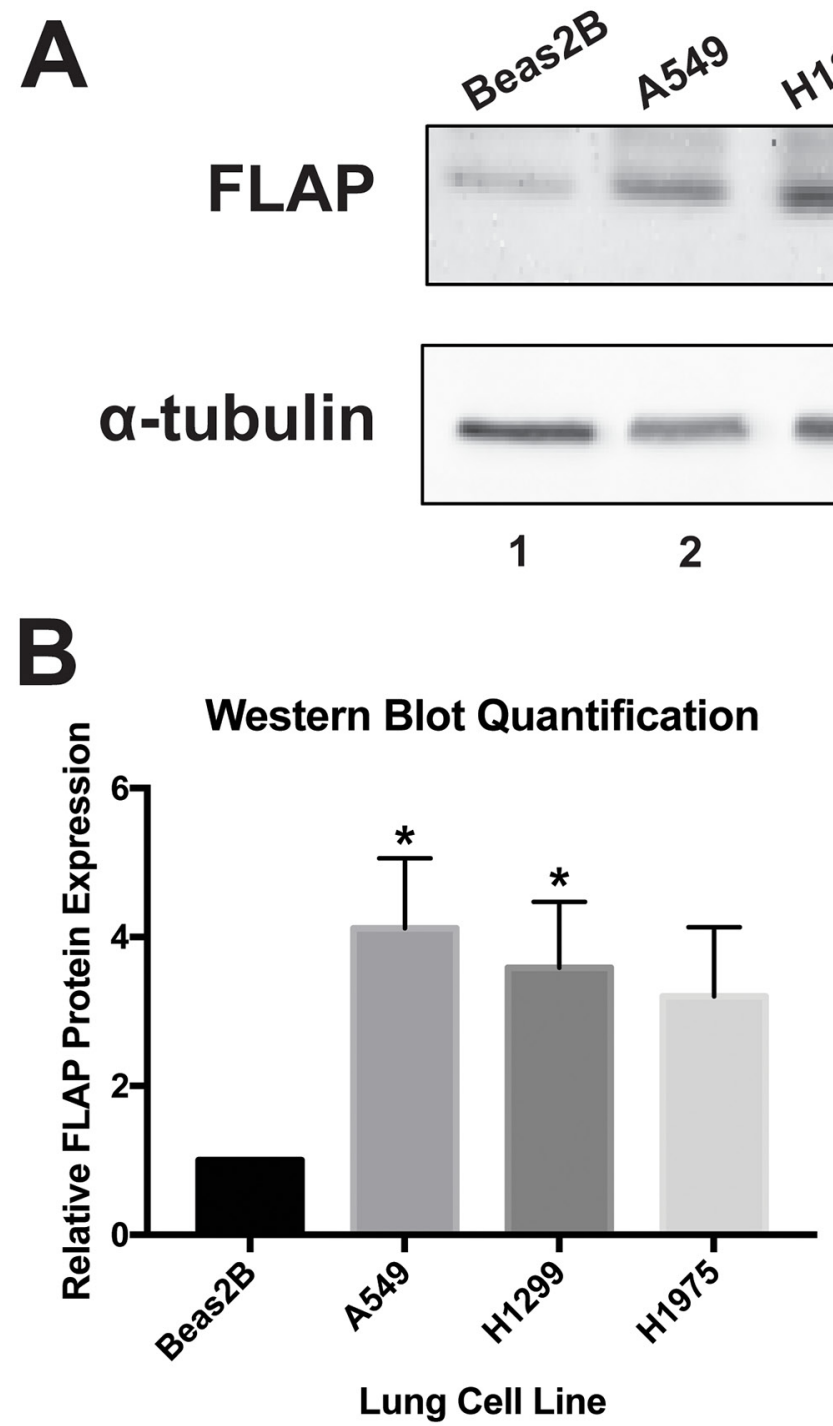

$18 \mathrm{kD}$

FLAP mRNA

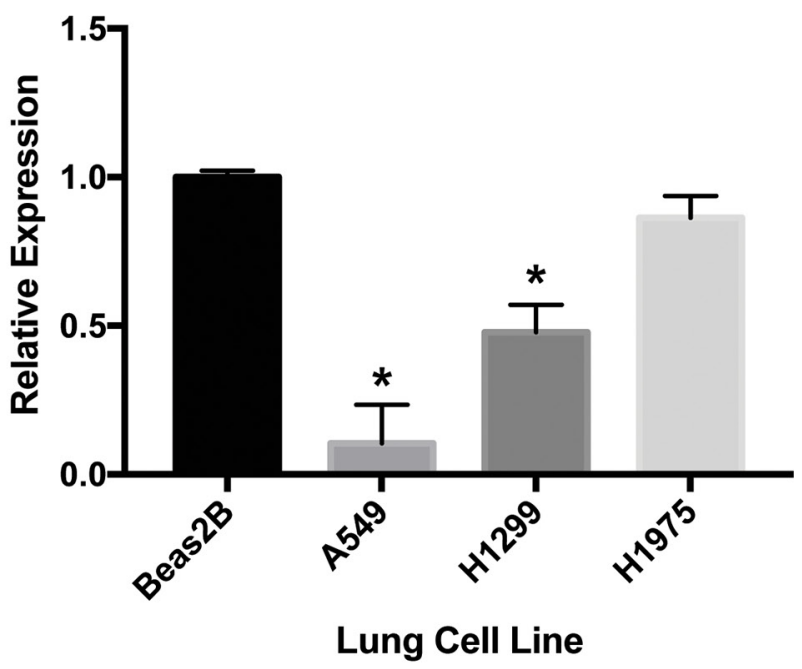

Figure 2: FLAP expression levels in lung cell lines. (A) Western blot analysis of Beas2B (normal lung), A549 (NSCLC), H1299 (NSCLC), and H1975 (NSCLC) cell lysates. Western blots were repeated at least three times. (B) Quantification of relative FLAP protein levels was performed using the gel analysis tool on ImageJ software and normalized to $\alpha$-tubulin protein levels. Analysis indicated significant overexpression of FLAP protein in A549 (lane 2) and H1299 cells (lane 3), but not H1975 cells (lane 4) with respect to Beas2B cells (lane 1). $\left(^{*}\right) P<0.04, n=3$. (C) $\triangle \Delta \mathrm{CT}$ qRT-PCR analysis indicated significantly increased expression of FLAP mRNA in Beas2B cells compared to A549 and H1299 cells, but not H1975 cells. FLAP expression was normalized to GAPDH mRNA. $\left({ }^{*}\right) P<0.01, n=3$. 
322 bp 3' UTR (Figure 3A and [2]). Expression of the protein isoform of the second splice variant has yet to be experimentally validated. The FLAP 3' UTR contains several putative miRNA binding sites. The miRNAs depicted in Figure 3A (binding sites represented as green lines) are predicted to target the FLAP 3' UTR based on two computational algorithms: miRanda (www.microrna. org) and TargetScan (www.targetscan.org). One such miRNA is miR-146a. This miRNA was of particular interest to us because we previously demonstrated that miR-146a directly regulates COX-2 expression and prostaglandin production in these lung cells [19]. The abovementioned algorithms suggest miR-146a can also directly regulate FLAP, another protein involved in inflammation and AA metabolism. Figure 3B shows the predicted alignment between mature miR-146a and the FLAP 3' UTR. The miR-146a-FLAP mRNA duplex has high complementarity at both the seed region $\left(5^{\prime}\right.$ end of the mature miRNA) and the miRNA $3^{\prime}$ end. This implies a high likelihood that miR-146a can bind to FLAP mRNA [42]. This potential interaction is further supported by the high evolutionary conservation of the miR-146a 7-mer seed sequence in the $3^{\prime}$ UTR of FLAP orthologs in various vertebrate species (Figure 3C).

miR-146a expression is significantly downregulated in A549, H1299, and H1975 cells compared to Beas2B cells (see Figure 4 of reference [19]) . Our lab previously established an inverse relationship between miR-146a and COX-2 protein expression in these lung cells [19]. A similar inverse relationship exists between miR-146a and FLAP protein expression. Thus, we hypothesize that miR146a regulates FLAP mRNA and therefore is involved in the resulting expression of FLAP protein. It is important to note that in our cells of interest, no mutation is present in the miR-146a binding site in the FLAP or COX-2 3' UTRs (data not shown) that may be responsible for the dysregulation seen in the cancer cells.

\section{Introduction of synthetic miR-146a represses endogenous FLAP expression}

To determine the effect of exogenous miR-146a on endogenous FLAP mRNA and protein, A549 cells were transfected with $50 \mathrm{nM}$ synthetic mature miR-146a. Another subset of A549 cells was transfected with 50 $\mathrm{nM}$ of a commercially available miRNA mimic with a sequence predicted to not target the human transcriptome. This non-targeting miRNA served as a control for nonspecific repression. All samples were compared to a mocktransfected group of A549 cells treated with transfection reagent alone. Protein and RNA were isolated from the cells 48 hours post-transfection. qRT-PCR was performed for FLAP mRNA expression and $\triangle \triangle \mathrm{CT}$ data analysis revealed a significant decrease in FLAP mRNA expression in A549 cells transfected with miR-146a (Figure 4A). Western blot analysis showed a similar repression of endogenous FLAP protein in miR-146a-treated cells (Figure 4B, 4C). The non-targeting miR showed no significant effect on FLAP mRNA or protein expression (Figure 4). In addition, increasing the miR-146a mimic concentration to $100 \mathrm{nM}$ showed a dose-dependent effect on FLAP protein levels (Figure 4D, 4E). Since miR-146a transfection resulted in a decrease in both FLAP mRNA and protein levels, our data do not conclusively prove whether miR-146a is mechanistically downregulating FLAP expression via mRNA degradation, translational repression, or both. However, it is clear that endogenous FLAP can be downregulated by miR-146a in A549 lung cells.

\section{Inducible miR-146a expression also decreases FLAP protein levels}

miRNA mimic experiments are limited by their transient nature. To examine the long-term effects of miR146a restoration on FLAP expression, stable clones of H1299 cells were generated with miR-146a expression under the control of the Tet Response Element (TRE). Using the Tet-On system, miR-146a overexpression occurs only when the cells are cultured in the presence of doxycycline (Figure 5A). Like A549 cells, H1299 cells are also derived from lung adenocarcinoma.

Using retroviral transduction, H1299 cells were generated expressing either the TRE empty vector or the TRE-miR-146a expression cassette (Figure 5A, Supplementary Figure 1). No significant difference in mature miR-146a expression was observed between H1299 TRE-empty cells cultured with or without $1 \mu \mathrm{g}$ / $\mathrm{mL}$ doxycycline (Figure 5B, right), controlling for the effect of this concentration of doxycycline. Relative to H1299 TRE-empty cells, mature miR-146a expression robustly increased ( $\sim 2000$-fold) in the H1299 TRE-miR146 a cells cultured in doxycycline (Figure 5B, left). Slight "leaky expression" was apparent, as H1299 TRE-miR146 a cells cultured without doxycycline showed a $\sim 14-$ fold increase in mature miR-146a expression (Figure 5B, right). Despite this leaky expression, a significant decrease in endogenous FLAP protein levels was only seen in H1299 TRE-miR-146a cells cultured in the presence of doxycycline (Figure 5C, 5D), suggesting higher degrees of induction are needed to see an effect on protein levels. This was similar to the observed repression in A549 cells transiently transfected with synthetic miR-146a (Figure 4). Using both a different cell line and expression method, these results support a role for miR-146a in the negative regulation of FLAP expression in lung cancer cell lines.

\section{Reporter protein activity is affected by direct miR-146a interaction with the FLAP 3' UTR}

To examine whether the effect of miR-146a on FLAP expression is directly controlled through its $3^{\prime}$ 


\section{A 5-Lipoxygenase Activating Protein (FLAP) 3' UTR}

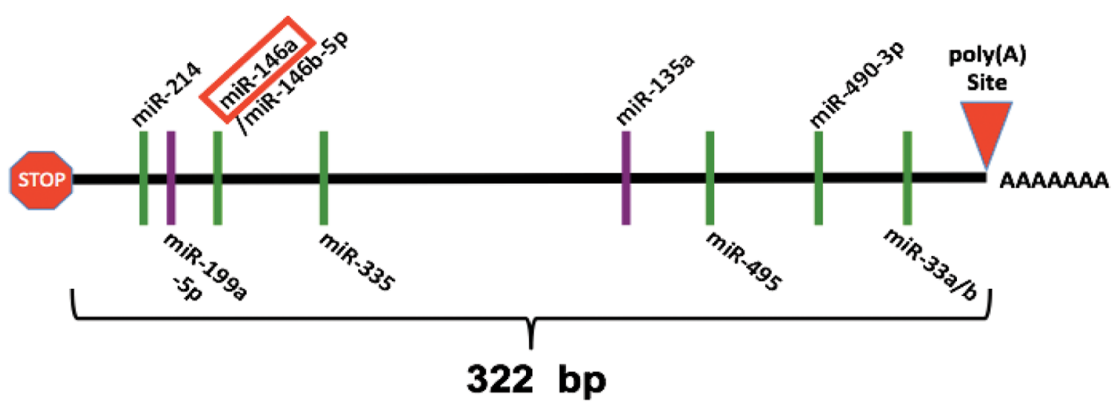

B

9

31

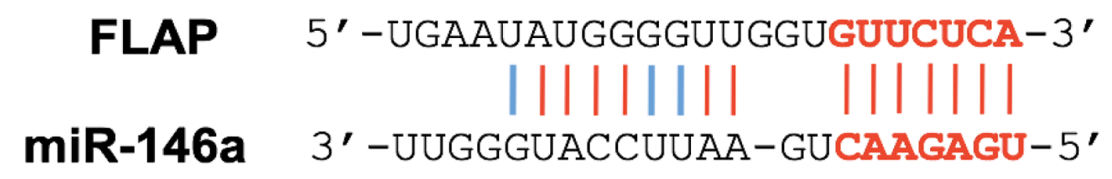

Conservation of miR-146a seed sequence in FLAP 3' UTR

\begin{tabular}{|c|c|c|}
\hline Human & $5^{\prime}$ & -GUUGGUGUUCUCAUCUAAUCAAU- 3 ' \\
\hline Chimpanzee & 5 ' & -GUUGGUGUUCUCAUCUAAUCAAU- 3 ' \\
\hline Rhesus & $5^{\prime}$ & -GUUGGUGUUCUCAUCUAAUCAAU- 3 ' \\
\hline Bushbaby & $5^{\prime}$ & -GUUGgUGUUCUCAUUUAAUCAAU- 3 ' \\
\hline Mouse & $5^{\prime}$ & -AGAAGCACGCUCACCAGAUCAAU- $3{ }^{\prime}$ \\
\hline Rat & $5^{\prime}$ & -AGUAGCACGAUCGCCAGAUCAAU- $3^{\prime}$ \\
\hline Guinea Pig & 5 ' & -GCUGGCACUCUCUGCUAAUCAAU- 3' \\
\hline Rabbit & $5^{\prime}$ & -GGCCGUGCGCUCAUGCGAUCGAU- 3 ' \\
\hline Shrew & $5^{\prime}$ & -GCUGUUGCUCUCAUCUAAUCAAU- 3 ' \\
\hline Dog & $5^{\prime}$ & -GUCAGCGCUCUCCUCUGAUCAAU- 3' \\
\hline Cat & $5^{\prime}$ & -GUCGGCACUUCCAUCUGAUCGAU- 3 ' \\
\hline Horse & $5^{\prime}$ & -GUUGGUGCUCUCAUCUAAUCAAU- 3 ' \\
\hline Cow & $5^{\prime}$ & -GUGGGUGUGCUCAGCUAAUCGAU- 3 ' \\
\hline Elephant & $5^{\prime}$ & -GUUGCUGCUCUCAUCUAAUCAAU- 3 ' \\
\hline Opossum & 5 ' & -AUCAGAGGUCUCAGCUAAUUAAU- 3 ' \\
\hline Platypus & $5^{\prime}$ & -GGCGGAGUCCUUCGCCGAUCAAU- 3' \\
\hline Lizard & $5^{\prime}$ & -GUCAGCAGCCUUCGCCAAUCAAU- 3 ' \\
\hline Chicken & $5^{\prime}$ & -GUCAGCCUGCUUCACAUAUCAAU- 3 ' \\
\hline & & $1 A U-3$ \\
\hline
\end{tabular}

Figure 3: miR-146a is predicted to target the FLAP 3' UTR. (A) Schematic illustration of the FLAP 3' UTR (not drawn to scale). The stop sign and red triangle represent the stop codon and polyadenylation site, respectively. Green lines indicate putative miRNA binding sites as predicted by the microRNA.org and TargetScan algorithms. Purple lines indicate miRNA binding sites validated in the literature. (B) Predicted alignment of miR-146a binding to the FLAP 3' UTR. The 7-mer seed sequence is highlighted in red and bold. Red lines indicate perfect complementarity and light blue lines indicate low-affinity U-G pairing. Numbers represent the base position within the $3^{\prime}$ UTR. (C) Diagram displaying the sequence conservation of the miR-146a seed sequence (highlighted in red) in the FLAP 3' UTR across various vertebrate species. Uppercase italic letters indicate conservation over at least 12 vertebrate species; lowercase italic letters indicate conservation over at least 9 vertebrate species. Sequences were obtained from TargetScan. 
UTR, luciferase reporter assays were performed. We purchased the pLightSwitch_3UTR Renilla luciferase reporter construct from Switch Gear Genomics. This plasmid contains the Renilla luciferase open reading frame (ORF) under the control of the constitutively active RPL10 promoter. We cloned the full-length FLAP 3' UTR (pLightSwitch_FLAP-WT 3' UTR) and GAPDH 3' UTR (pLightSwitch_GAPDH 3' UTR) downstream of the Renilla luciferase ORF (Figure 6A). These reporter assays were carried out in HeLa cells to avoid interference from endogenous FLAP mRNA levels in Beas2B, A549, or H1299 cells. HeLa cells do not express FLAP mRNA or protein (data not shown). The cells were mock-treated or transfected with synthetic miR-146a or non-targeting miR. Transfection with the abovementioned luciferase constructs was performed afterwards. Relative FLAP 3' UTR Renilla luciferase activity decreased $\sim 50 \%$ only in the cells treated with miR-146a (Figure 6B). These data suggest that the observed repression of FLAP expression (Figure 4 and 5) is carried out by miR-146a via the FLAP 3' UTR.

Next, the FLAP 3' UTR Renilla luciferase assay was repeated in the presence of a miR-146a antagomiR (anti-miR-146a) in order to ensure our observations were specific. This antagomiR works by sequestering miR-146a and preventing it from interacting with its targets. HeLa cells were mock-treated or transfected with miR-146a alone, anti-miR-146a alone, or miR-146a/anti-miR-146a together. Luciferase construct transfection followed, as above. When the antagomiR sequestered miR-146a, the relative FLAP

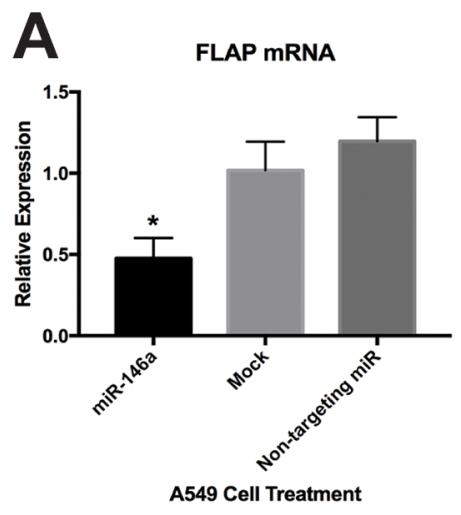

D

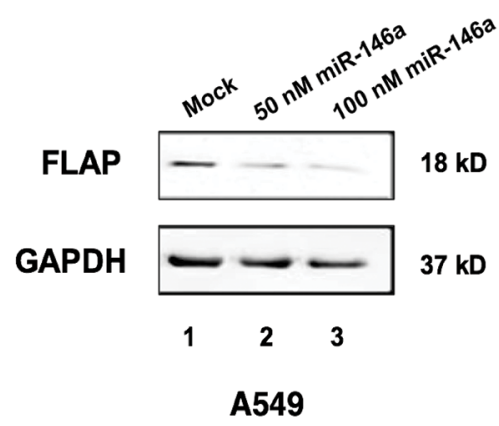

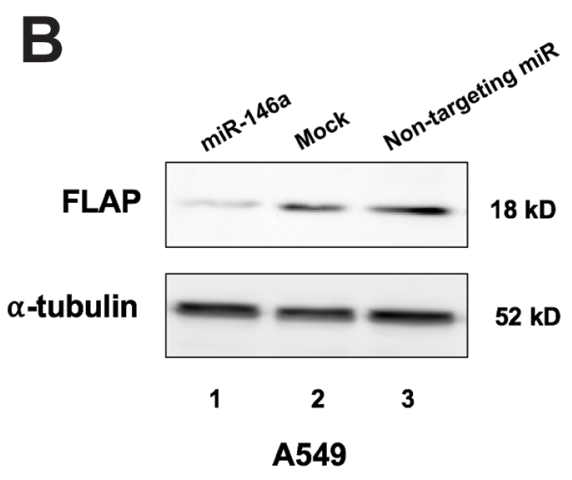
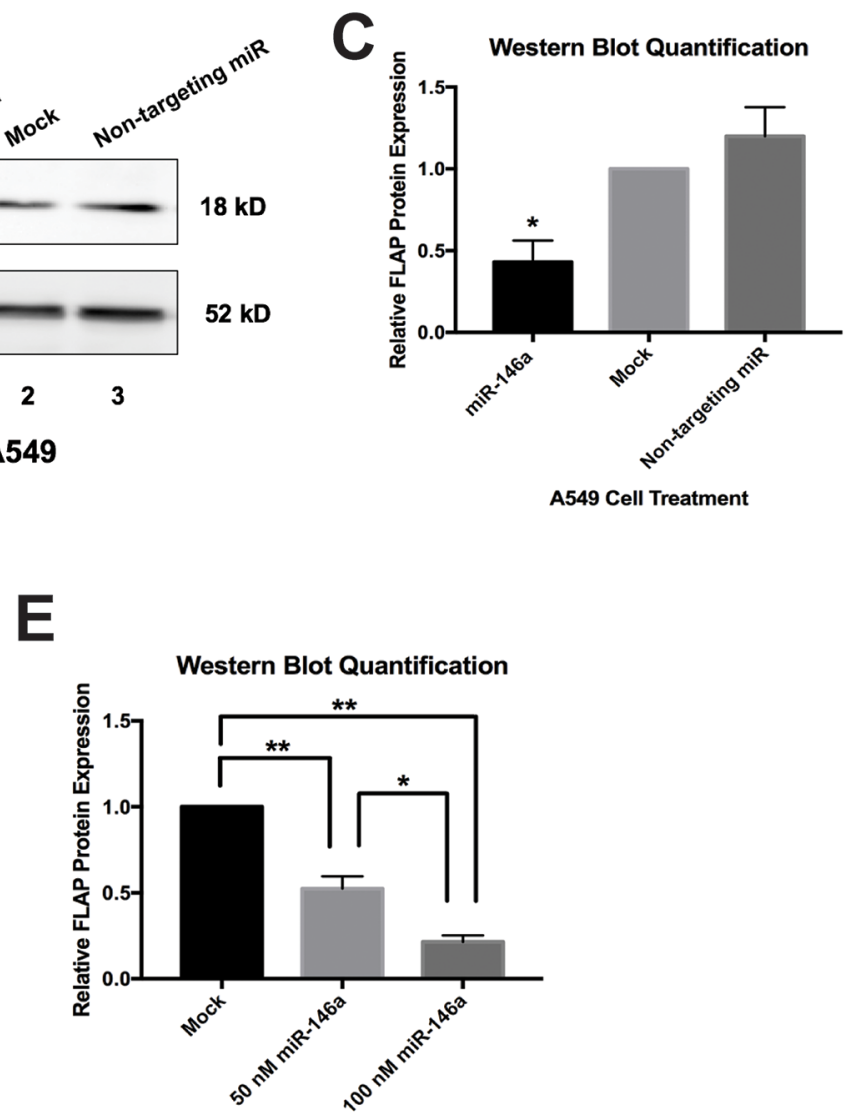

Figure 4: Synthetic miR-146a represses endogenous FLAP mRNA and protein in A549 cells. A549 cells were transiently transfected with miRNA mimics. Cells were lysed and RNA and protein were isolated 48 hours post-transfection. (A) $\Delta \Delta C T$ qRT-PCR analysis indicated decreased FLAP mRNA expression in A549 cells transfected with $50 \mathrm{nM}$ miR-146a. FLAP expression was normalized to GAPDH mRNA. FLAP mRNA levels were significantly different in cells transfected with miR-146a from levels in mock-treated cells and cells transfected with $50 \mathrm{nM}$ non-targeting miRNA. $\left(^{*}\right) P<0.01, n=3$. (B) Western blot analysis of cell lysates indicated decreased FLAP protein expression in A549 cells transfected with $50 \mathrm{nM}$ miR-146a (lane 1) compared to mock-treated A549 cells (lane 2) and A549 cells transfected with $50 \mathrm{nM}$ non-targeting miRNA (lane 3). A representative blot is shown of three independent experiments. (C) Quantification of relative FLAP protein levels was performed using the gel analysis tool on ImageJ software and normalized to $\alpha$-tubulin protein levels. ( ${ }^{*} P<0.01, n=3$. (D) Western blot analysis of cell lysates indicated dose-dependent decreased FLAP protein expression in A549 cells transfected with 50 and $100 \mathrm{nM}$ miR-146a (lanes 2 and 3) compared to mock-treated A549 cells (lane 1). A representative blot is shown of three independent experiments. (E) Quantification of relative FLAP protein levels was performed using the gel analysis tool on ImageJ software and normalized to GAPDH protein levels. $\left(^{*}\right) P<0.035,\left({ }^{* *}\right) P<0.025, n=3$. 
3' UTR Renilla luciferase activity significantly increased to similar levels as the mock-treated cells. In addition, anti-miR-146a alone did not affect luciferase activity (Figure 6C). These results further support a specific interaction between miR-146a and the FLAP 3' UTR that consequentially drives FLAP downregulation.
In order to further understand the nature of the miR$146 \mathrm{a}$ effect, it was necessary to determine whether miR146 a directly interacts with the FLAP 3' UTR through a specific sequence. The FLAP 3' UTR contains a single computationally predicted miR-146a binding site that begins $\sim 10-15$ nucleotides downstream of the stop codon
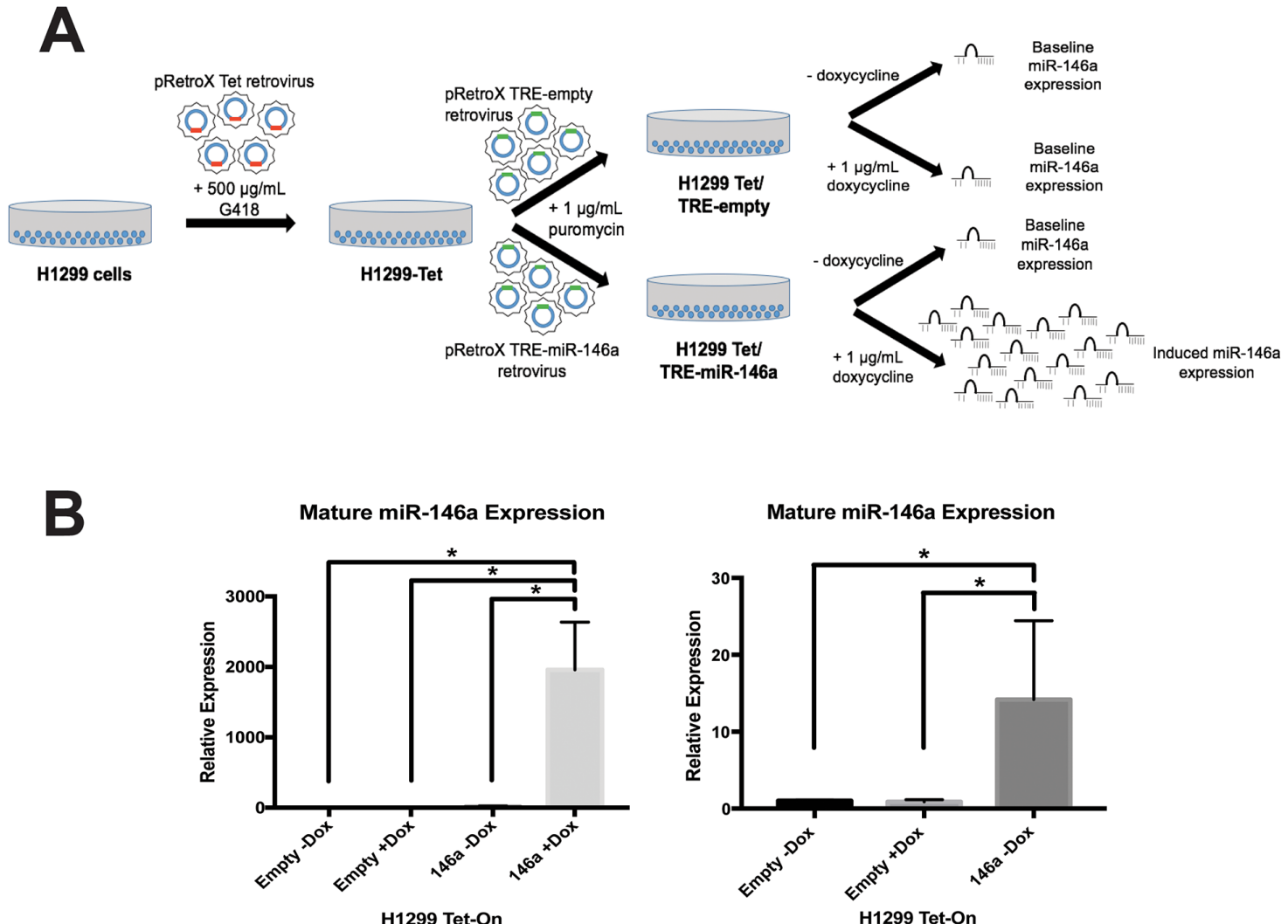

B
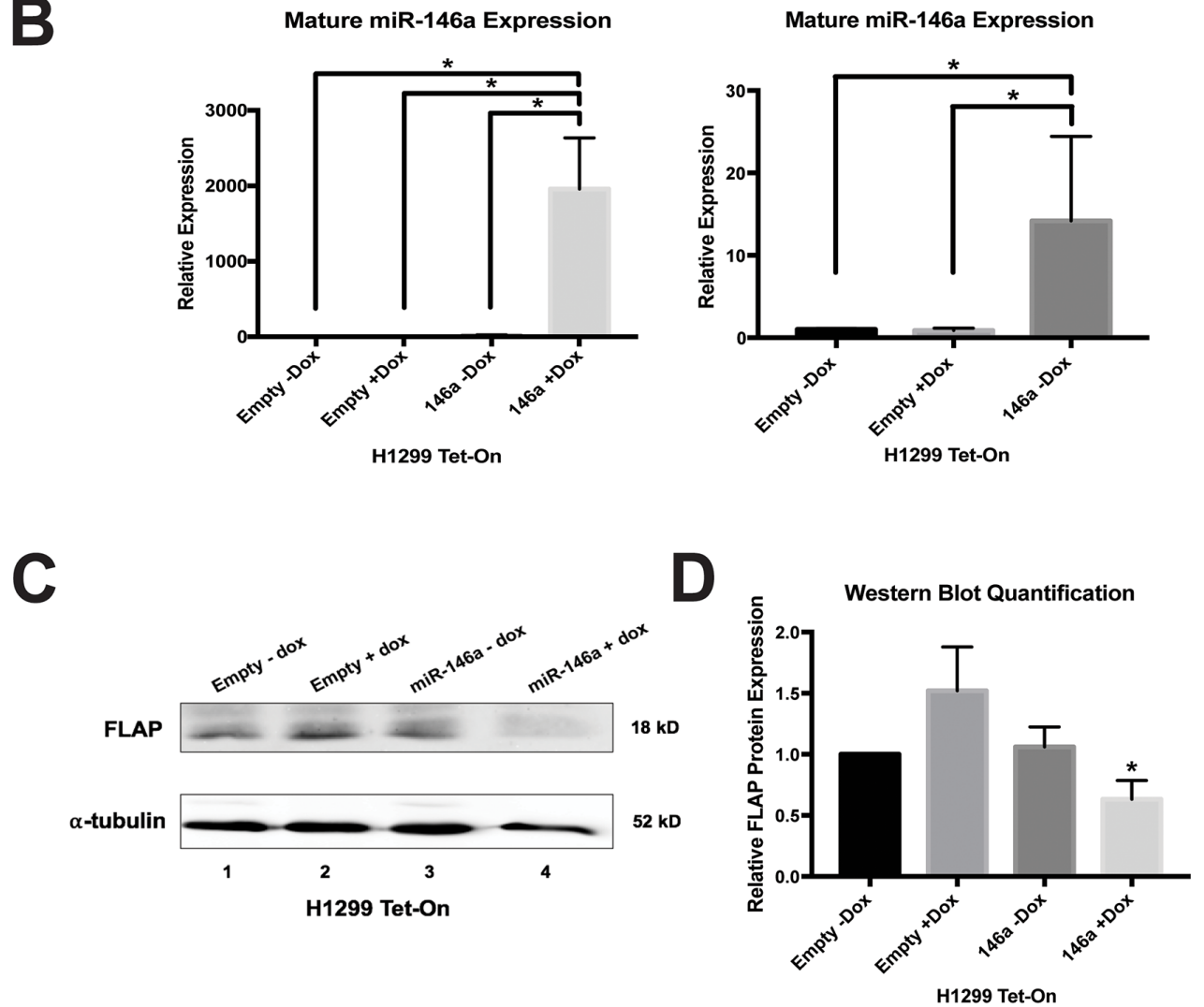

Figure 5: Doxycycline-induced expression of miR-146a in H1299 cells represses endogenous FLAP protein. (A) Schematic illustration of methodology used for stable cell line development (see methods section for more details). Where indicated, H1299 Tet/TRE-empty and H1299 Tet/TRE-miR-146a cells were cultured in $1 \mu \mathrm{g} / \mathrm{mL}$ doxycycline. (B) Left: $\Delta \Delta C \mathrm{CT}$ qRT-PCR analysis indicated successful induction of mature miR-146a expression in H1299 Tet/TRE-miR-146a cells. miR-146a expression was normalized to U6 snRNA expression. Right: Focused graph showing miR-146a expression in control cell lines. $\left(^{*}\right) P<0.03, n=3$. (C) Western blot analysis of cell lysates indicated decreased FLAP protein expression only in H1299 Tet/TRE-miR-146a cells cultured with doxycycline. A representative blot is shown of three independent experiments. (D) Quantification of relative FLAP protein levels was performed using the gel analysis tool on ImageJ software and normalized to $\alpha$-tubulin protein levels. $\left(^{*}\right) P<0.037, n=3$. 
(Figure 3). Literature suggests the seed region is crucial for miRNA function [42]. Therefore, 4 nucleotides in the 7-mer miR-146a seed sequence in the FLAP 3' UTR luciferase construct were mutated using site-directed mutagenesis (TTCT to CCGC) (Figure 6A). HeLa cells were transfected with synthetic miRs and luciferase
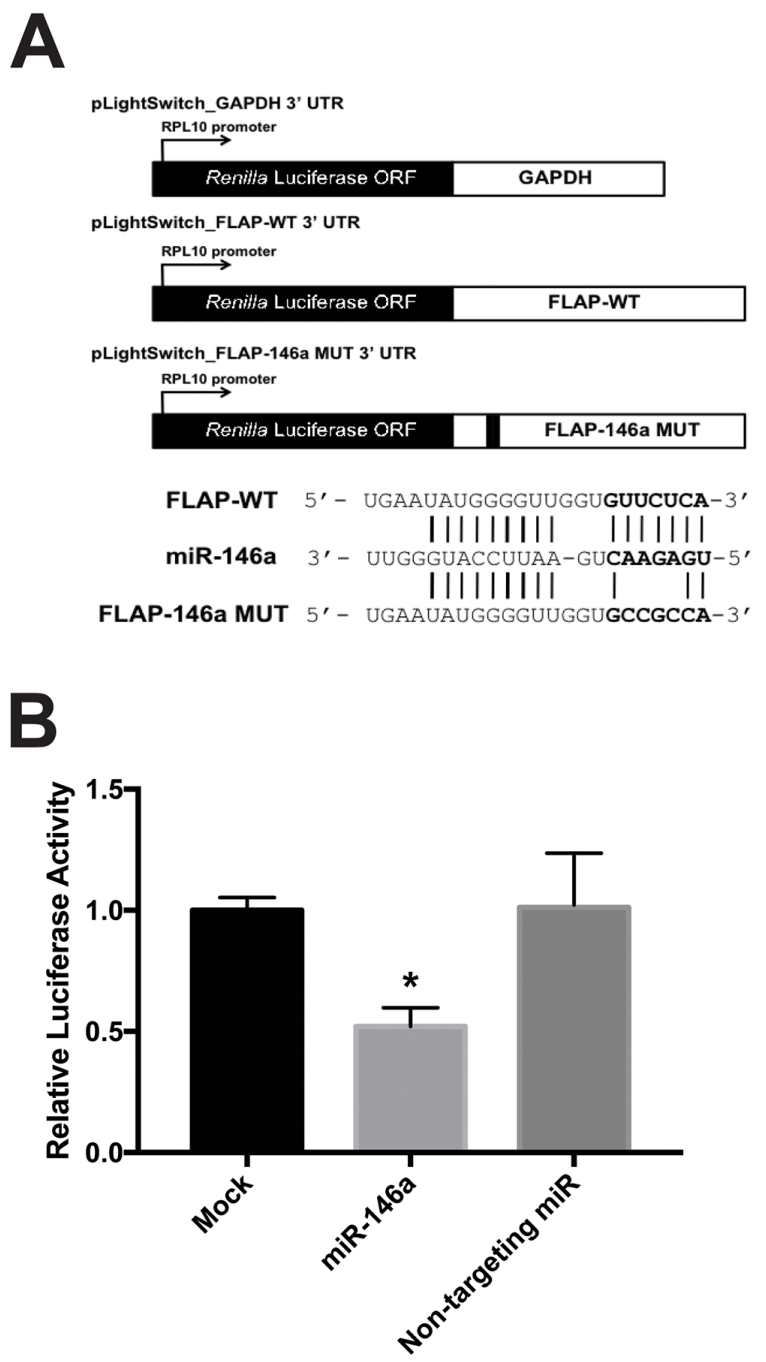

Figure 6: miR-146a directly targets the FLAP 3' UTR. (A, top) Schematic illustration of the Renilla luciferase $3^{\prime}$ UTR constructs used: pLightSwitch_GAPDH 3' UTR, pLightSwitch_FLAP-WT 3' UTR, and pLightSwitch FLAP-146a MUT 3' UTR. (A, bottom) Predicted alignment of miR-146a binding to the FLAP WT 3' UTR. The 7-mer seed sequence is highlighted in bold. Lines indicate perfect complementarity and potential low-affinity U-G pairing. The alignment is also shown for miR-146a binding to the FLAP $3^{\prime}$ UTR containing a 4-nt mutation (UUCU-CCGC) in the FLAP-146a MUT 3' UTR construct. (B) Renilla luciferase activity was measured in HeLa cells transfected with $50 \mathrm{nM}$ synthetic miRNAs (miR-146a or non-targeting miR) and the pLightSwitch_FLAP-WT 3' UTR construct. FLAP WT 3' UTR luciferase activity was normalized to GAPDH 3' UTR luciferase activity in HeLa cells exposed to the same miRNA condition. Luciferase activity was further normalized to total protein concentration of each sample. Renilla luciferase activity was significantly decreased only in samples treated with miR-146a. ( $\left.{ }^{*}\right) P<0.002, n=6$. (C) FLAP-WT 3' UTR Renilla luciferase activity was measured in HeLa cells transfected with $50 \mathrm{nM}$ miR-146a alone, $50 \mathrm{nM}$ anti-miR-146a alone, or $50 \mathrm{nM}$ of both miR-146a and anti-miR-146a. Luciferase activity was normalized as described above in B. Renilla luciferase activity in cells treated with miR-146a and its antagomiR together was significantly greater than in cells treated with miR-146a alone. $\left(^{*}\right) P<0.001, n=5$. (D) FLAP-WT 3' UTR and FLAP-146a MUT 3' UTR Renilla luciferase activities were measured in HeLa cells transfected with $50 \mathrm{nM}$ synthetic miRNAs (miR-146a or non-targeting miR). Luciferase activity was normalized as described above in B. FLAP-146a MUT 3' UTR Renilla luciferase activity was significantly higher than FLAP-WT 3' UTR Renilla luciferase activity in cells treated with miR-146a due to the mutation in the miR-146a binding site. $\left(^{*}\right) P<$ $0.01, n=3$. 
3' UTR construct containing a mutated miR-146a seed sequence (Figure 6D). These observations suggest miR146a-mediated repression of FLAP expression is executed through a direct interaction between miR-146a and a binding site in the FLAP 3' UTR.

\section{Leukotriene $\mathrm{B} 4$ production is decreased by introduction of miR-146a}

FLAP and 5-LO work in concert to convert AA to the intermediate $\mathrm{LTA}_{4}$, which can be processed by a number of other enzymes into various LTs. One of these lipid signaling molecules is $\mathrm{LTB}_{4}$. $\mathrm{LTB}_{4}$ has been described as a pro-inflammatory and pro-tumorigenic LT, as well as one of the most potent LTs [13]. We previously showed A549 cells produce lower levels of Prostaglandin $\mathrm{E}_{2}\left(\mathrm{PGE}_{2}\right)$ following miR-146a transfection [19]. Because our data showed miR-146a transfection resulted in modulated levels of FLAP protein, we were interested to see if this downregulation also affects $\mathrm{LTB}_{4}$ production. To investigate this, we performed an enzymelinked immunosorbent assay (ELISA) specific for LTB This assay was carried out on mock-treated A549 cells and cells transiently transfected with miR-146a or a nontargeting miR. Analysis revealed a significant decrease in $\mathrm{LTB}_{4}$ release in cells treated with miR-146a. The nontargeting miR did not display this effect (Figure 7A). We also performed this assay on the H1299 Tet-On stable cells and observed significantly reduced $\mathrm{LTB}_{4}$ production only in the H1299 TRE-146a cells cultured in the presence of doxycycline (Figure 7B). These results imply miR-146amediated regulation of FLAP also causes a decrease in its biological function. It is important to note that in a previous study, our lab had shown transfection of synthetic miRNAs at a $50 \mathrm{nM}$ concentration in A549 cells does not result in significant levels of cytotoxicity that could potentially account for the observed decrease in eicosanoid production (see Figure 7B of reference [19]).

\section{The miR-146a promoter is highly methylated at CpG sites in lung cancer cell lines}

We previously established that miR-146a expression is significantly downregulated in A549, H1299, and H1975 cells compared to Beas $2 \mathrm{~B}$ cells (see Figure 4 of reference 19), but the mechanism for this remained unclear. It is important to note that in our cells of interest, no mutation is present in the pri-miR-146a genomic sequence, nor is there a miRNA processing defect, that may be responsible for the dysregulation seen in the cancer cells (data not shown). miR-146a expression is suppressed in lung cancer

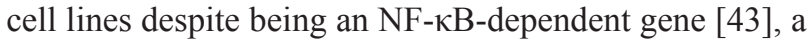
pathway which is often constitutively active in lung cancer [44]. Because hypermethylation of tumor suppressor gene promoters is frequently observed in cancers, we predicted that this may be responsible for lower miR-146a levels in lung cancer. We analyzed a 491 bp genomic sequence upstream of the miR-146a transcriptional start site which was identified by David Baltimore's lab as the miR-146a promoter [43]. The promoter sequence contains $21 \mathrm{CpG}$ sites (Figure 8A).

Next, we treated A549 cells for 24 hours with 5-aza2'-deoxycytidine, which inhibits DNA methyltransferase activity. qRT-PCR analysis indicated this treatment resulted in a 2-3 fold increase in mature miR-146a expression (Figure 8B), suggesting DNA methylation may be playing a role in miR-146a expression in A549 cells. In order to detect DNA methylation status, we designed methylation-specific PCR (MSP) primers for two regions of the miR-146a promoter sequence. These assays revealed that A549 and H1299 cells had significantly higher methylation levels at these two regions than Beas2B cells (Figure 8C, 8D). H1975 cells also had a higher methylation status, but the data were only statistically significant for region 2 (Figure 8C, 8D). Region 3 does not have a sufficient density of $\mathrm{CpG}$ sites for MSP analysis. Our results suggest promoter $\mathrm{CpG}$ hypermethylation is responsible for repressed miR-146a expression in lung cancer cell lines.

Overall, our data show miR-146a can downregulate FLAP expression in lung cancer cells by directly targeting its 3' UTR. This modulation in FLAP protein levels results in decreased lung cancer cell production of $\mathrm{LTB}_{4}$, and miR-146a expression is regulated by DNA methylation.

\section{DISCUSSION}

In this communication, we have identified FLAP as a novel target of miR-146a. We have demonstrated that an inverse relationship exists between FLAP protein expression and miR-146a expression in lung cancer cell lines as compared to Beas2B cells. In lung cancer cell lines, the FLAP expression level is high (Figure 2) but the miR-146a levels are low [19]. In contrast, Beas2B cells show robust expression of miR-146a but low FLAP protein expression (Reference [19] and Figure $2)$. In silico analyses suggest FLAP expression levels negatively correlate with lung adenocarcinoma patient overall survival (Figure 1) and the miR-146a binding site in the FLAP 3' UTR is highly conserved throughout evolution (Figure 3). Transient (Figure 4) and stable (Figure 5) transfection of miR-146a in lung cell lines resulted in reduced endogenous FLAP expression. Luciferase assays demonstrated the direct and specific nature of the interaction of miR-146a with FLAP mRNA (Figure 6). The biological effect of miR-146a on FLAP was revealed by the observation of significantly reduced $\mathrm{LTB}_{4}$ production in the presence of miR-146a (Figure 7) as compared to control treatments. Finally, $\mathrm{CpG}$ methylation is the likely mechanism responsible for suppressed miR-146a expression in lung cancer cells (Figure 8). 
Our data suggest a model, shown in Figure 9. Expression of miR-146a is regulated by promoter $\mathrm{CpG}$ methylation. Methylation is increased in lung cancer cells, resulting in significantly less mature miR-146a. This leads to increased protein levels of miR-146a target genes COX2 [19] and FLAP (this work), which ultimately allows the cell to produce greater amounts of $\mathrm{PGE}_{2}$ and $\mathrm{LTB}_{4}$. Post-transcriptional regulation of COX-2 and FLAP via

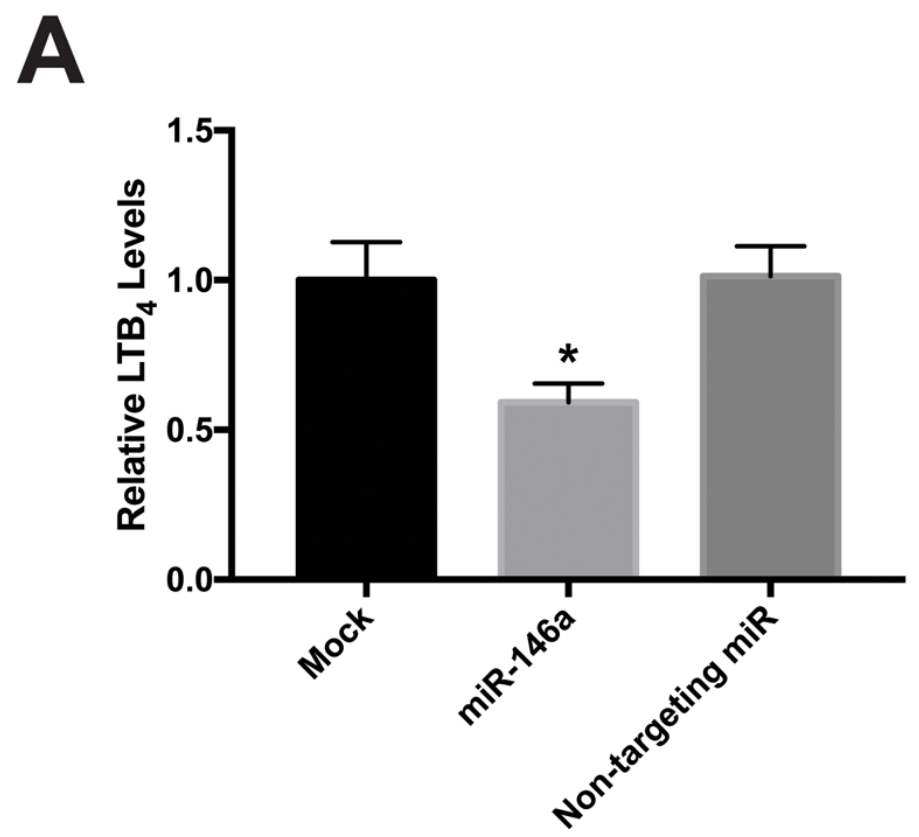

A549 Cell Treatment
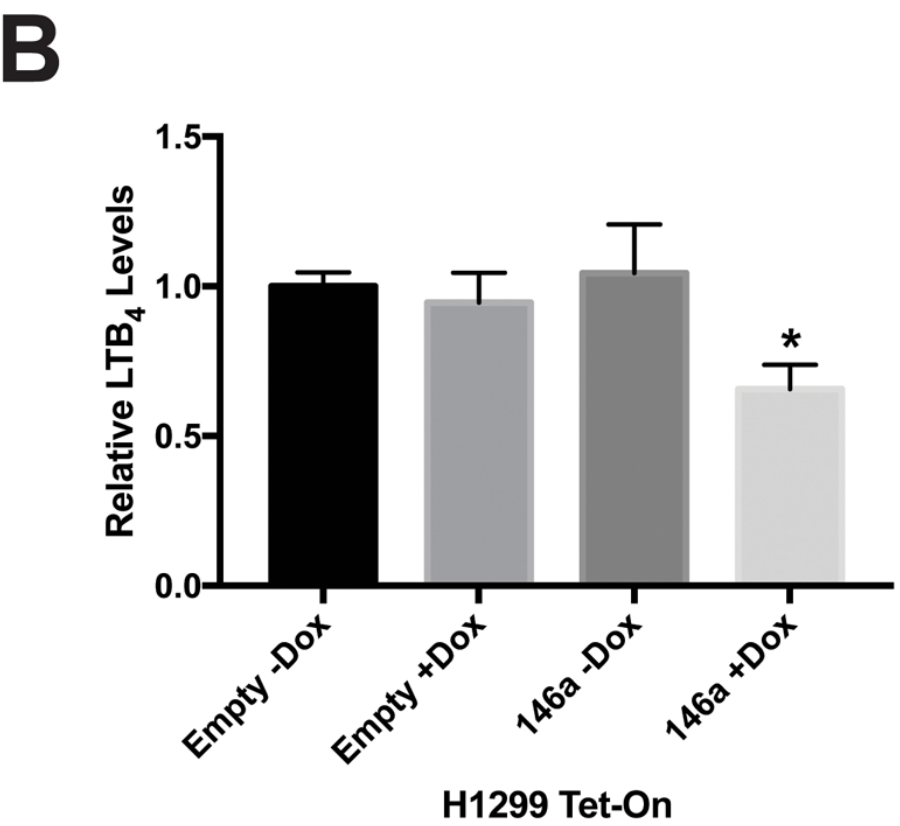

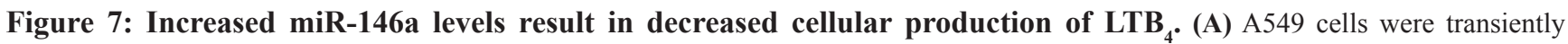
transfected with $50 \mathrm{nM}$ miRNA mimics. Cell-free, serum-free supernatants were collected 48 hours post-transfection. An enzyme-linked immunosorbent assay (ELISA) was used to measure Leukotriene B4 (LTB $)_{4}$ concentrations. A549 cells transfected with miR-146a produced significantly less $\mathrm{LTB}_{4}$ compared to mock-treated cells and cells transfected with a non-targeting miRNA. $\left(^{*}\right) P<0.025, n=3$. (B) Where indicated, H1299 Tet/TRE-empty and H1299 Tet/TRE-miR-146a cells were cultured in $1 \mu \mathrm{g} / \mathrm{mL}$ doxycycline. Cell-free, serumfree supernatants were collected and an ELISA was used to measure LTB $_{4}$ concentrations. H1299 Tet/TRE-miR-146a cells cultured in doxycycline produced significantly less $\mathrm{LTB}_{4} \cdot\left(^{*}\right) P<0.04, n=3$. 
A

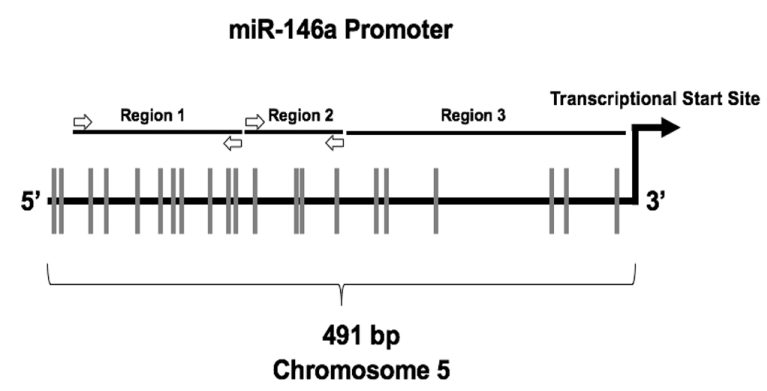

C

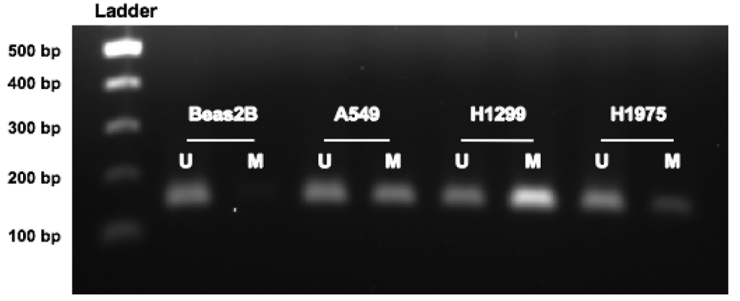

D

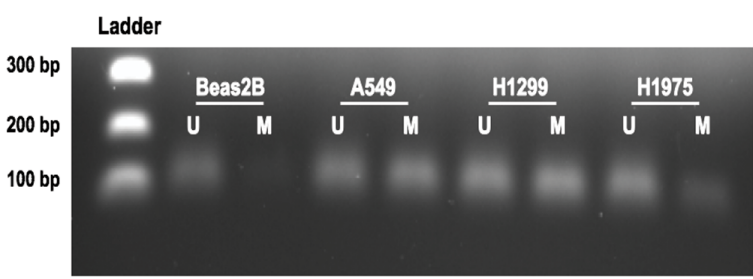

A549 Mature miR-146a Expression

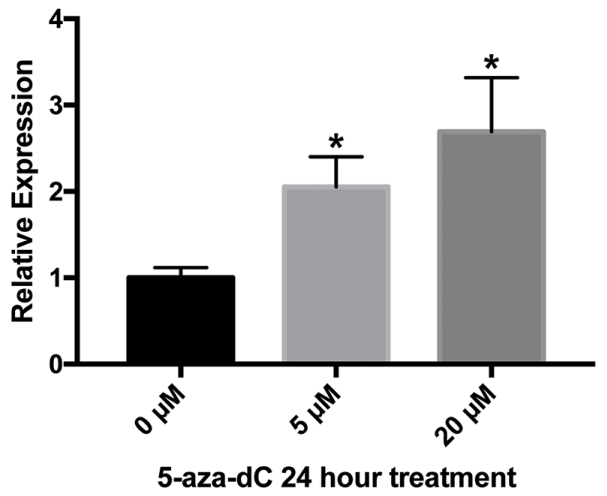

miR-146a Promoter Region 1 CpG Methylation

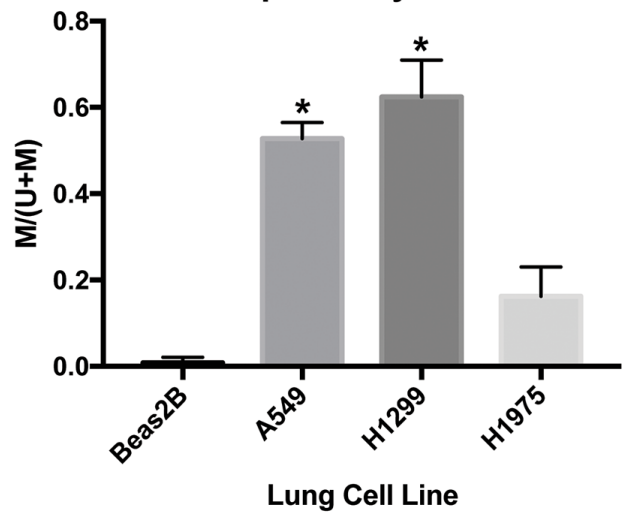

miR-146a Promoter Region 2 CpG Methylation

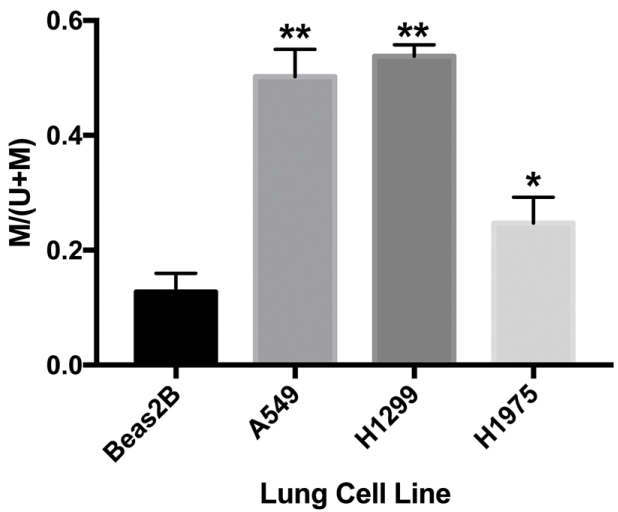

Figure 8: miR-146a expression is regulated by CpG methylation in lung cell lines. (A) Schematic illustration depicting the miR-146a promoter region (not drawn to scale). Vertical lines indicate $\mathrm{CpG}$ sites. Primer annealing locations for methylation-specific PCR (MSP) are shown as white arrows. (B) $\triangle \Delta$ CT qRT-PCR analysis indicated increased expression of mature miR-146a in A549 cells following 5-aza-2'-deoxycytidine (5-aza-dC) treatment. miR-146a expression was normalized to U6 snRNA expression. $\left(^{*}\right) P<0.03$, $n=3$. (C) Left: MSP products for miR-146a promoter region 1 in four lung cell lines run on a 1\% agarose gel. Representative gel of three independent experiments is shown. Right: Image J software was used to measure band intensities. The intensity of the methylated band divided by total band intensity for each cell line is shown. ( $\left.{ }^{*}\right) P<0.006, n=3$. (D) Left: MSP products for miR-146a promoter region 2 in four lung cell lines run on a $1 \%$ agarose gel. Representative gel of three independent experiments is shown. Right: Image J software was used to measure band intensities. The intensity of the methylated band divided by total band intensity for each cell line is shown. $\left(^{*}\right) P<$ $0.025,\left({ }^{* *}\right) P<0.001, n=3$. U: unmethylated state; M: methylated state. 
miR-146a is an endogenous mechanism by which the cell can control metabolism of AA into both PGs and LTs. The biological significance of targeting both arms of the pathway has recently become apparent in multiple reports discussing AA shunting. The concept of shunting was first suggested when researchers observed that inhibition of one arm of the pathway lead to upregulation of the other arm. One group noted that when they induced an acute inflammatory response in 5-LO knockout mice, administering a cyclooxygenase inhibitor was able to resolve the inflammation, but it was unable to do so in wild-type mice [45]. Guo et al. reported that COX-2 was upregulated in 5-LO knockout mice that had oral cancer induced with ethanol [46]. Manigrasso and O'Connor observed 4-fold higher levels of LTs in femur fracture calluses of COX-2 knockout mice, showing that shunting can go in both directions [12]. This phenomenon has also been shown in multiple studies involving siRNAs as well as celecoxib, a selective COX-2 inhibitor, indicating shunting is not an experimental artifact [47-49]. While the interplay of AA metabolic pathway components remains to be fully elucidated, it is clear that the relationship between the two arms is quite important. The simultaneous targeting of COX-2 and FLAP by miR-146a in lung cells therefore suggests there is an intricate network of control over AA metabolism and balance of eicosanoid signaling.

In addition to its role in regulation of COX2 expression in lung cancer cells [19], miR-146a has recently been identified as a negative regulator of immune function, innate and adaptive immune responses, and hematopoiesis $[50,51]$. The most well established targets of miR-146a are IRAK1/2 (IL-1 receptor-associated kinase 1/2) and TRAF6 (TNF receptor-associated factor 6) mRNAs, which encode important adaptor molecules in the Toll-like receptor pathway and cytokine responses that lead to NF- $\kappa$ B activation [43, 52-55]. miR-146a itself is an NF- $\kappa \mathrm{B}$-dependent gene, and is part of a negative feedback loop controlling this pathway [43]. Here, we have demonstrated for the first time that miR-146a specifically mediates and downregulates the production of pro-inflammatory LTs. Thus, we postulate that miR$146 \mathrm{a}$ acts in both arms of the AA biochemical pathway to fine-tune the response to pro-inflammatory stimuli so as to avoid a chronic and/or overstimulatory response. In

\section{A Normal Lung Cells}

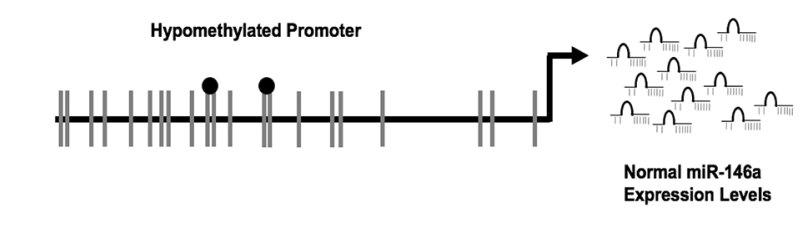

B

B Lung Cancer Cells
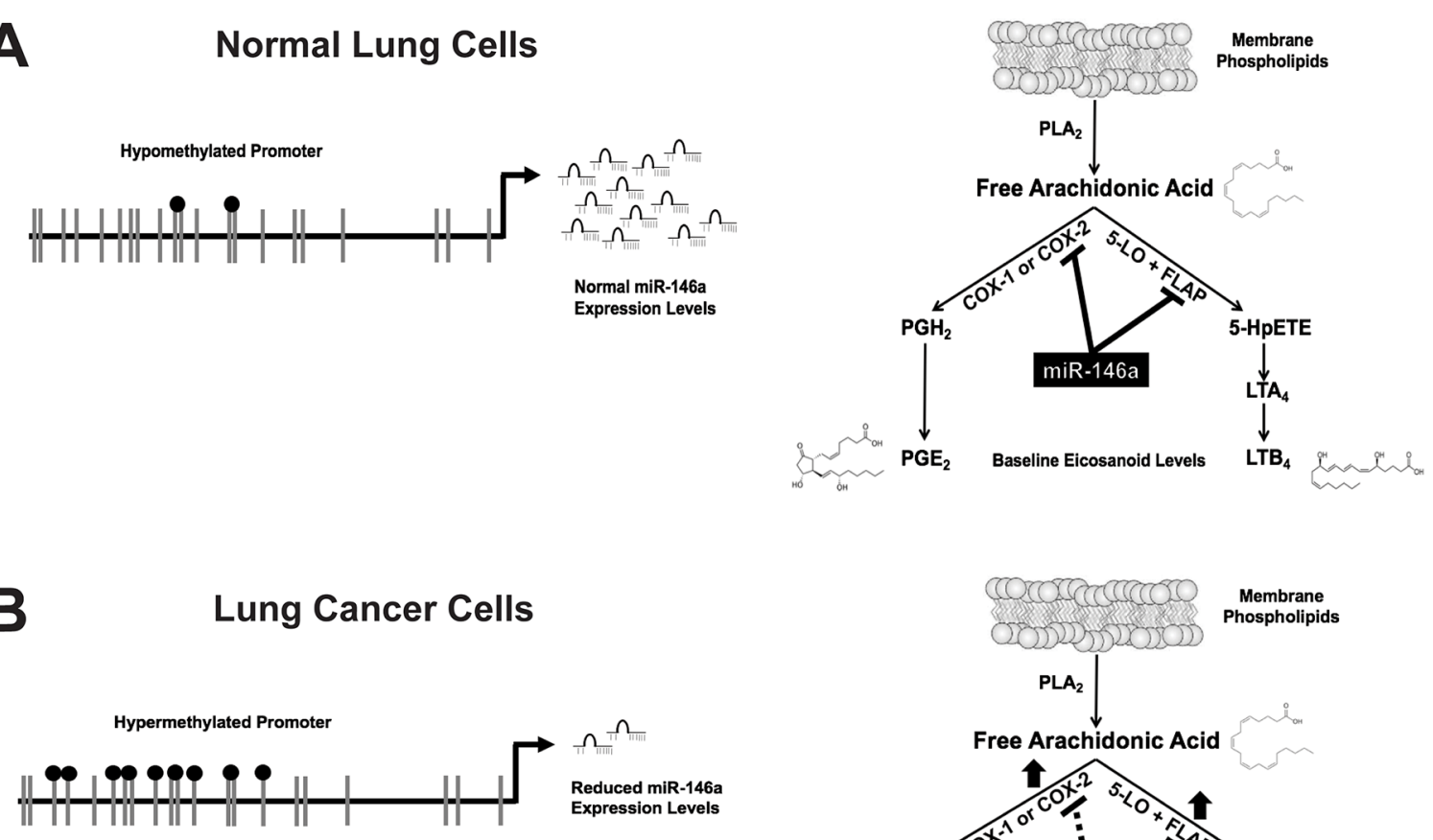

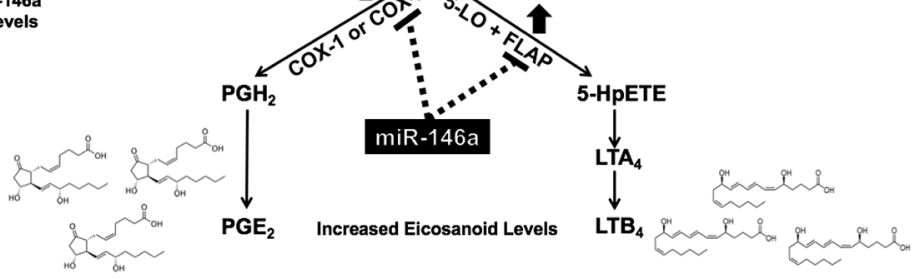

Figure 9: miR-146a negatively regulates both the prostaglandin and leukotriene arms of the arachidonic acid metabolic pathway. (A) In normal lung cells, a hypomethylated promoter allows miR-146a to be expressed. miR-146a directly targets COX-2 and FLAP, which controls $\mathrm{PGE}_{2}$ and $\mathrm{LTB}_{4}$ production. (B) In lung cancer cells, a hypermethylated promoter results in reduced miR-146a expression. This leads to increased COX-2 and FLAP protein expression, and therefore higher levels of $\mathrm{PGE}_{2}$ and $\mathrm{LTB}_{4}$. Adapted in part from: [14]. 
lung cancer cells, this regulation is likely affected in that there is significantly reduced miR-146a expression due to promoter hypermethylation, leading to overexpression of the AA metabolic proteins and increased production of their downstream products.

Additionally, both of our studies on miR-146a in lung cancer cells revealed a significant decrease in cellular release of pro-inflammatory PGs and LTs in response to miR-146a treatment. This further supports the biological relevance of our findings. $\mathrm{PGE}_{2}$ and $\mathrm{LTB}_{4}$ act on epithelial cells in an autocrine and paracrine manner by binding to their specific $G$ protein-coupled receptors, which activate signaling cascades that directly control cell proliferation, survival, migration, and invasion (reviewed in reference [13]). $\mathrm{PGE}_{2}$ and $\mathrm{LTB}_{4}$ can also participate in crosstalk with the surrounding stromal cells leading to increased angiogenesis [56] and immunosuppression [57] within the tumor microenvironment. Published work from other labs has shown that restoration of miR-146a expression in lung cancer cell lines results in decreased cell migration, proliferation, and growth, as well as increased apoptosis [58, 59], suggesting that this miRNA may be useful as a novel targeted therapeutic. A growing number of researchers are now advocating for dual inhibition of the PG and LT arms of AA metabolism to treat various cancers. Combined knockdown of 5-LO and COX-2 with siRNAs resulted in a more significant decrease in head and neck squamous cell carcinoma cell proliferation in vitro than with COX-2 inhibition alone [48]. COX-2/5-LO dual inhibition also resulted in a more robust decrease in colon tumor growth in a nude mouse xenograft model [49]. Our work now demonstrates that miR-146a is an endogenous dual inhibitor of this biochemical pathway.

\section{MATERIALS AND METHODS}

\section{Mammalian cell culture}

Beas2B and A549 cells (ATCC) were grown in Dulbecco's Modified Eagle's Medium (DMEM, SigmaAldrich), HeLa cells (ATCC) were grown in Minimal Essential Medium Eagle (Sigma-Aldrich), and H1299 and H1975 cells (ATCC) were grown in Roswell Park Memorial Institute-1640 Medium (Sigma-Aldrich). All media were supplemented with 10\% FBS, $4 \mathrm{mM}$ L-glutamine, and 1\% Penicillin/Streptomycin, and cells were incubated at $37^{\circ} \mathrm{C}$ in a $5 \% \mathrm{CO}_{2}$ incubator. Please note that our strain of Beas $2 \mathrm{~B}$ cells does not cause tumors in nude mice [60].

\section{Kaplan-Meier survival analysis}

The Kaplan-Meier Plotter online tool specific for NSCLC (www.kmplot.com) was used to analyze any potential correlation between overall survival and FLAP expression. This tool was generated using compiled data from multiple cancer patient transcriptomic studies and $\mathrm{R}$ statistical software [40]. FLAP expression was designated to be low or high in patients based on their relation to the median value. The KM Plotter tool then generated survival curves, and logrank $\mathrm{P}$ values and hazard ratios (HR) with $95 \%$ confidence intervals were calculated and plotted in $\mathrm{R}$.

\section{Western blot analysis}

Cells were washed with $1 \mathrm{X}$ PBS then lysed with RIPA buffer (50 nM Tris- $\mathrm{HCl} \mathrm{pH} 7.4,1 \% \mathrm{NP}-40,0.5 \%$ sodium deoxycholate, $0.1 \% \mathrm{SDS}, 150 \mathrm{mM} \mathrm{NaCl}, 1 \%$ protease inhibitor cocktail). Cells were lysed for 30 minutes on ice with occasional stirring. Lysed cells in RIPA were centrifuged at $14,000 \mathrm{x}$ g at $4^{\circ} \mathrm{C}$ for $15 \mathrm{~min}$. Protein concentration was determined using detergentcompatible (DC) Bradford Assay analysis (Bio-Rad) according to the manufacturer's protocol. Western blot analysis was performed by separating protein samples with 10\% SDS-PAGE. Wet electrophoretic transfer to nitrocellulose membrane $\left(80 \mathrm{~V}, 2\right.$ hours, $\left.4^{\circ} \mathrm{C}\right)$ was performed, then followed by blocking with 5\% nonfat milk + PBSt (5\% non-fat dry milk, 1X PBS, 0.1\% Tween-20 [Sigma-Aldrich]) for at least 1 hour at room temperature. Primary and secondary antibodies were diluted in 5\% non-fat milk + PBSt. Blots were incubated in primary antibodies overnight at $4^{\circ} \mathrm{C}$. Post-primary incubation, the blots were washed 3 times for 5 min with PBSt. Blots were then incubated in secondary antibodies for 1-2 hours at room temperature, then washed the same as post-primary incubations. Proteins were detected using HyGlo Quick Spray (Denville Scientific) and a chemiluminescence detection instrument (myECL, Thermo Fisher Scientific). FLAP (EPR5640) rabbit primary monoclonal antibody was purchased from Abcam and diluted 1:1000. $\alpha$-tubulin horseradish peroxidase (HRP)-conjugated and GAPDH HRP-conjugated antibodies were purchased from ProteinTech and diluted 1:2000. Goat anti-rabbit HRP-conjugated secondary antibody was purchased from Thermo Fisher Scientific and diluted 1:2000. All antibodies were diluted in 5\% nonfat milk + PBSt. All Western blots were performed at least three times. Quantification was performed using the gel analysis tool on ImageJ software.

\section{Quantitative real-time RT-PCR (qRT-PCR)}

Total RNA was isolated from cells using TRIzol (Invitrogen) following the manufacturer's protocol. Complementary DNA (cDNA) was synthesized by reverse transcription of RNA using M-MLV Reverse Transcriptase according to the manufacturer's protocol (Invitrogen). For mature miRNA analysis, cDNA was synthesized by reverse transcription of RNA using the miScript kit (Qiagen). qRTPCR was performed using a Bio-Rad CFX96 Real-Time C1000 Touch Thermal Cycler and the following cycling conditions: (1) $95^{\circ} \mathrm{C}$ for $15 \mathrm{~min}$, (2) 40 cycles of $94^{\circ} \mathrm{C}$ for $15 \mathrm{sec}, 55^{\circ} \mathrm{C}$ for $30 \mathrm{sec}, 70^{\circ} \mathrm{C}$ for $30 \mathrm{sec}$ (collection step). 
Please see Supplementary Table 1 for relevant primer sequences. Expression was measured with SYBR Green/ ROX qPCR master mix (Thermo Fisher Scientific). No template and no Reverse Transcriptase (-RT) controls were implemented to ensure samples were not contaminated. Melt curve analysis and electrophoresis of amplified products were performed as well. Quantitative Comparative $\mathrm{CT}(\Delta \Delta \mathrm{CT})$ analysis was used to analyze gene expression changes relative to GAPDH or U6. qRT-PCR data represent the average of at least three independent experiments. Each sample was measured with $n \geq 2$ technical replicates per target gene per independent experiment.

\section{MicroRNA transfection}

Synthetic versions of miR-146a and nontargeting miRNAs were purchased from Dharmacon. Hsa-miR-146a-5p mature microRNA sequence: 5'-UGAGAACUGAAUUCCAUGGGUU-3'. Dharmacon's miRIDIAN microRNA Mimic Negative Control \#1 (sequence is not provided) was used as a non-targeting miRNA. A miRNA inhibitor (antagomiR) specific for miR-146a, anti-hsa-miR-146a-5p, was purchased from Qiagen. Lung cell lines were transiently transfected with synthetic miRs at the indicated concentrations using INTERFERin transfection reagent (Polyplus) according to the manufacturer's protocol. Western blot and qRT-PCR analyses were performed on cells 48 hours post-transfection.

\section{Doxycycline-induced miR-146a expression}

Clones of H1299 cells inducibly expressing miR$146 \mathrm{a}$ in the presence of doxycycline were generated using the Retro-X Tet-On 3G inducible expression system (Clontech). The pRetroX Tet $3 \mathrm{G}$ vector was used to produce retroviruses according to the manufacturer's suggested protocol. A preliminary cell line stably expressing the Tet transactivator protein (H1299-Tet) was created by transducing H1299 cells with these retroviruses and selecting with $500 \mu \mathrm{g} / \mathrm{mL}$ G418. A $616 \mathrm{bp}$ fragment including the full miR-146a genomic sequence and flanking regions was cloned into the pRetroX TRE 3G vector using the BamHI and EcoRI sites. TRE-empty and TRE-miR-146a retroviruses were produced and used to transduce H1299-Tet cells, followed by selection with $1 \mu \mathrm{g} / \mathrm{mL}$ puromycin. Cells surviving both G418 and puromycin selection were diluted and plated in 96-well plates such that there was approximately one cell per well. Single clones were grown up and analyzed individually. H1299 Tet/ TRE-empty and H1299 Tet/TRE-miR-146a cells were cultured, where indicated, in $1 \mu \mathrm{g} / \mathrm{mL}$ doxycycline. All cells were cultured in RPMI supplemented with 10\% Tet System Approved FBS (Clontech) and $4 \mathrm{mM}$ L-glutamine.

\section{Plasmids}

The pLightSwitch_3UTR Renilla luciferase reporter vector was purchased from SwitchGear Genomics. The FLAP and GAPDH 3' UTR fragments were cloned into the multiple cloning site downstream of RenSP, the optimized Renilla luciferase open reading frame under the control of the RPL10 constitutively active promoter. pLightSwitch_FLAP146a MUT 3' UTR, a construct containing the FLAP 3' UTR fragment with a 4-nt mutation (TTCT - CCGC) in the miR-146a seed sequence, was generated using the GeneArt site-directed mutagenesis system (Invitrogen). Please see Supplementary Table 1 for relevant primer sequences.

\section{Luciferase assays}

HeLa cells were seeded in a 12 -well plate format at a density of $0.5 \times 10^{5}$ cells/well. Twenty-four hours after seeding, cells were transfected with a synthetic miRNA (miR-146a, non-targeting miRNA, or anti-miR-146a) at $50 \mathrm{nM}$ as described above (see microRNA transfection). Twenty hours post-miR transfection, cells were transfected with luciferase constructs (pLightSwitch_FLAP-WT 3' UTR, pLightSwitch_FLAP-146a MUT 3' UTR, or pLightSwitch_GAPDH 3' UTR) using LipoD293 transfection reagent (SignaGen Laboratories) according to the manufacturer's suggested protocol. Thirty hours postDNA transfection, cells were washed with cold 1X PBS and lysed with $250 \mu \mathrm{L}$ 1X Passive Lysis Buffer (Promega). Renilla luciferase activity (luminescence) was measured using the Renilla-Glo luciferase assay system (Promega). Briefly, $50 \mu \mathrm{L}$ of each lysate was added to a well of a 96well black-bottom plate and incubated with $50 \mu \mathrm{L}$ of $1 \mathrm{X}$ Renilla-Glo Luciferase Assay Reagent (Promega) for 10 min at room temperature in the dark. Luminescence was then read using a plate reader. Renilla luciferase activity from pLightSwitch_FLAP-WT 3' UTR or pLightSwitch FLAP-146a MUT 3' UTR was normalized to activity obtained from samples transfected with pLightSwitch GAPDH 3' UTR under the same miR-condition. Samples were further normalized to the protein concentration of each lysate as determined by a Bradford assay. All assays were conducted in independent triplicates, and each individual experiment was repeated at least three times.

\section{Enzyme-linked immunosorbent assay (ELISA)}

Transiently transfected A549 cells were incubated in serum-free media and stimulated with $4 \mu \mathrm{M}$ calcium ionophore (A23817, Sigma) for $30 \mathrm{~min}$ prior to collecting supernatants [61]. H1299 Tet-On cells were incubated in serum-free media containing $10 \mu \mathrm{M}$ arachidonic acid (Cayman Chemical) for 30 min. Supernatants were removed from the cells and centrifuged at 2,000 x g, $10 \mathrm{~min}, 4^{\circ} \mathrm{C}$. These cell-free supernatants were then analyzed using the Leukotriene B4 EIA Kit (Cayman Chemical) according to the manufacturer's provided protocol. The data 
represent the average of three independent experiments. Each sample was measured with $n \geq 2$ technical replicates.

\section{Methylation analysis}

A549 cells were seeded in $60 \mathrm{~mm}$ dishes at a density of $3 \times 10^{5} \mathrm{cells} / \mathrm{dish}$. The next day, cells were treated with indicated concentrations of 5-aza-2'-deoxycytidine (Sigma-Aldrich). DMSO alone was used as a control treatment. All cells were harvested 24 hours post-treatment and RNA analysis was performed as described above.

Analysis of a $491 \mathrm{bp}$ sequence upstream of the miR-146a transcriptional start site [43] was performed for the presence of $\mathrm{CpG}$ sites. Methyl Primer Express v1.1 [62] was used to design methylation-specific PCR (MSP) primers for two regions of this promoter sequence. Please see Supplementary Table 1 for primer sequences. Genomic DNA (gDNA) was isolated from lung cell lines using the DNeasy Blood and Tissue Kit (Qiagen) following the protocol for purification of total DNA from cultured animal cells. These gDNA samples were modified using the EpiTect Bisulfite Kit (Qiagen) following the main protocol provided by the manufacturer. Modified gDNA was amplified with MSP primers using the following cycling conditions: (1) $94^{\circ} \mathrm{C}$ for $2 \mathrm{~min}$, (2) 35 cycles of $94^{\circ} \mathrm{C}$ for $30 \mathrm{sec}, 55^{\circ} \mathrm{C}$ for $30 \mathrm{sec}, 72^{\circ} \mathrm{C}$ for $30 \mathrm{sec}$. PCR products were analyzed with agarose gel electrophoresis and ethidium bromide staining. Band intensities were quantified using the gel analysis tool on ImageJ software. The experiment was repeated three times for each region.

\section{Data analysis}

Data are expressed as mean \pm 1 SD. Significance was determined using a two-tailed independent sample Student's $t$-test using GraphPad Prism 7.0a. $P$-values $<0.05$ were considered significant.

\section{Author contributions}

JRI and CSL conceived and designed the experiments. JRI performed the experiments, analyzed the data, and wrote the paper. NJM assisted with performing experiments and analyzing data contained in Figures 2 and 4. All authors reviewed the results and approved the final version of the manuscript.

\section{ACKNOWLEDGMENTS}

We thank past and present members of the Lutz laboratory and our colleagues at Rutgers Biomedical and Health Sciences for helpful discussions and suggestions. We are grateful to Ms. Anita Antes for her assistance with cell culture. We would like to thank Utz Herbig, Ph.D., of Rutgers for providing us with the Retro-X Tet-On $3 \mathrm{G}$ vectors.

\section{CONFLICTS OF INTEREST}

The authors declare that they have no conflicts of interest with the contents of this article.

\section{FUNDING}

We thank the New Jersey Commission on Cancer Research (NJCCR; Pre-Doctoral Fellowship to JRI), the American Heart Association (Grant-in-aid 15GRNT23240019 to CSL) and the NJCCR for a Bridge Grant to CSL. Research reported in this publication was supported by the National Institute Of Arthritis And Musculoskeletal And Skin Diseases of the National Institutes of Health under Award Number R01AR069044. The content is solely the responsibility of the authors and does not necessarily represent the official views of the National Institutes of Health.

\section{REFERENCES}

1. Dixon RA, Diehl RE, Opas E, Rands E, Vickers PJ, Evans JF, Gillard JW, Miller DK. Requirement of a 5-lipoxygenase-activating protein for leukotriene synthesis. Nature. 1990; 343:282-4. https://doi.org/10.1038/343282a0.

2. Lutz CS, Cornett AL. Regulation of genes in the arachidonic acid metabolic pathway by RNA processing and RNAmediated mechanisms. Wiley Interdiscip Rev RNA. 2013; 4:593-605. https://doi.org/10.1002/wrna.1183.

3. Hafner AK, Gerstmeier J, Hornig M, George S, Ball AK, Schroder M, Garscha U, Werz O, Steinhilber D. Characterization of the interaction of human 5-lipoxygenase with its activating protein FLAP. Biochim Biophys Acta. 2015; 1851:1465-72. https://doi.org/10.1016/j. bbalip.2015.08.010

4. Kennedy BP, Diehl RE, Boie Y, Adam M, Dixon RA. Gene characterization and promoter analysis of the human 5-lipoxygenase-activating protein (FLAP). J Biol Chem. 1991; 266:8511-6.

5. Funk CD, Hoshiko S, Matsumoto T, Rdmark O, Samuelsson B. Characterization of the human 5-lipoxygenase gene. Proc Natl Acad Sci U S A. 1989; 86:2587-91.

6. Hla T, Neilson K. Human cyclooxygenase-2 cDNA. Proc Natl Acad Sci U S A. 1992; 89:7384-8.

7. Williams CS, Mann M, DuBois RN. The role of cyclooxygenases in inflammation, cancer, and development. Oncogene. 1999; 18:7908-16. https://doi.org/10.1038/ sj.onc. 1203286 .

8. Simon AM, Manigrasso MB, O'Connor JP. Cyclooxygenase 2 function is essential for bone fracture healing. $\mathrm{J}$ Bone Miner Res. 2002; 17:963-76. https://doi.org/10.1359/ jbmr.2002.17.6.963

9. Wenzel SE. The role of leukotrienes in asthma. Prostaglandins Leukot Essent Fatty Acids. 2003; 69:145-55. 
10. Evans JF, Ferguson AD, Mosley RT, Hutchinson JH. What's all the FLAP about?: 5-lipoxygenase-activating protein inhibitors for inflammatory diseases. Trends Pharmacol Sci. 2008; 29:72-8. https://doi.org/10.1016/j.tips.2007.11.006.

11. Cottrell JA, O'Connor JP. Pharmacological inhibition of 5-lipoxygenase accelerates and enhances fracture-healing. J Bone Joint Surg Am. 2009; 91:2653-65. https://doi. org/10.2106/JBJS.H.01844.

12. Manigrasso MB, O'Connor JP. Accelerated fracture healing in mice lacking the 5-lipoxygenase gene. Acta Orthop. 2010; 81:748-55. https://doi.org/10.3109/17453674.2010. 533931 .

13. Wang D, Dubois RN. Eicosanoids and cancer. Nat Rev Cancer. 2010; 10:181-93. https://doi.org/10.1038/nrc2809.

14. O'Connor JP, Manigrasso MB, Kim BD, Subramanian S. Fracture healing and lipid mediators. Bonekey Rep. 2014; 3:517. https://doi.org/10.1038/bonekey.2014.12.

15. Radmark O, Werz O, Steinhilber D, Samuelsson B. 5-Lipoxygenase, a key enzyme for leukotriene biosynthesis in health and disease. Biochim Biophys Acta. 2015; 1851:331-9. https://doi.org/10.1016/j.bbalip.2014.08.012.

16. Hall-Pogar T, Liang S, Hague LK, Lutz CS. Specific transacting proteins interact with auxiliary RNA polyadenylation elements in the COX-2 3'-UTR. RNA. 2007; 13:1103-15. https://doi.org/10.1261/rna.577707.

17. Hall-Pogar T, Zhang H, Tian B, Lutz CS. Alternative polyadenylation of cyclooxygenase-2. Nucleic Acids Res. 2005; 33:2565-79. https://doi.org/10.1093/nar/gki544.

18. Young LE, Moore AE, Sokol L, Meisner-Kober N, Dixon DA. The mRNA stability factor HuR inhibits microRNA-16 targeting of COX-2. Mol Cancer Res. 2012; 10:167-80. https://doi.org/10.1158/1541-7786.MCR-11-0337.

19. Cornett AL, Lutz CS. Regulation of COX-2 expression by miR-146a in lung cancer cells. RNA. 2014; 20:1419-30. https://doi.org/10.1261/rna.044149.113.

20. Luo M, Lee S, Brock TG. Leukotriene synthesis by epithelial cells. Histol Histopathol. 2003; 18:587-95.

21. Zaman K, Hanigan MH, Smith A, Vaughan J, Macdonald T, Jones DR, Hunt JF, Gaston B. Endogenous S-nitrosoglutathione modifies 5-lipoxygenase expression in airway epithelial cells. Am J Respir Cell Mol Biol. 2006; 34:387-93. https://doi.org/10.1165/rcmb.2005-0336RC.

22. Chung SW, Toriba A, Chung HY, Yu BP, Kameda T, Tang N, Kizu R, Hayakawa K. Activation of 5-lipoxygenase and NF-kappa B in the action of acenaphthenequinone by modulation of oxidative stress. Toxicol Sci. 2008; 101:1528. https://doi.org/10.1093/toxsci/kfm252.

23. Avis I, Martinez A, Tauler J, Zudaire E, Mayburd A, AbuGhazaleh R, Ondrey F, Mulshine JL. Inhibitors of the arachidonic acid pathway and peroxisome proliferatoractivated receptor ligands have superadditive effects on lung cancer growth inhibition. Cancer Res. 2005; 65:418190. https://doi.org/10.1158/0008-5472.CAN-04-3441.
24. Tong WG, Ding XZ, Talamonti MS, Bell RH, Adrian TE. LTB4 stimulates growth of human pancreatic cancer cells via MAPK and PI-3 kinase pathways. Biochem Biophys Res Commun. 2005; 335:949-56. https://doi.org/10.1016/j. bbrc.2005.07.166.

25. Ihara A, Wada K, Yoneda M, Fujisawa N, Takahashi H, Nakajima A. Blockade of leukotriene B4 signaling pathway induces apoptosis and suppresses cell proliferation in colon cancer. J Pharmacol Sci. 2007; 103:24-32.

26. Bachi AL, Kim FJ, Nonogaki S, Carneiro CR, Lopes JD, Jasiulionis MG, Correa M. Leukotriene B4 creates a favorable microenvironment for murine melanoma growth. Mol Cancer Res. 2009; 7:1417-24. https://doi. org/10.1158/1541-7786.MCR-09-0038.

27. Schneider C, Pozzi A. Cyclooxygenases and lipoxygenases in cancer. Cancer Metastasis Rev. 2011; 30:277-94. https:// doi.org/10.1007/s10555-011-9310-3.

28. Avis IM, Jett M, Boyle T, Vos MD, Moody T, Treston AM, Martinez A, Mulshine JL. Growth control of lung cancer by interruption of 5-lipoxygenase-mediated growth factor signaling. J Clin Invest. 1996; 97:806-13. https://doi. org/10.1172/JCI118480.

29. Chen Y, Hu Y, Zhang H, Peng C, Li S. Loss of the Alox5 gene impairs leukemia stem cells and prevents chronic myeloid leukemia. Nat Genet. 2009; 41:783-92. https://doi. org/10.1038/ng.389.

30. Wasilewicz MP, Kolodziej B, Bojulko T, Kaczmarczyk M, Sulzyc-Bielicka V, Bielicki D, Ciepiela K. Overexpression of 5-lipoxygenase in sporadic colonic adenomas and a possible new aspect of colon carcinogenesis. Int $\mathrm{J}$ Colorectal Dis. 2010; 25:1079-85. https://doi.org/10.1007/ s00384-010-0980-z.

31. Sarveswaran S, Chakraborty D, Chitale D, Sears R, Ghosh J. Inhibition of 5-lipoxygenase selectively triggers disruption of c-Myc signaling in prostate cancer cells. J Biol Chem. 2015; 290:4994-5006. https://doi.org/10.1074/ jbc.M114.599035.

32. Sarveswaran S, Thamilselvan V, Brodie C, Ghosh J. Inhibition of 5-lipoxygenase triggers apoptosis in prostate cancer cells via down-regulation of protein kinase C-epsilon. Biochim Biophys Acta. 2011; 1813:2108-17. https://doi.org/10.1016/j.bbamcr.2011.07.015.

33. Kim JH, Hubbard NE, Ziboh V, Erickson KL. Attenuation of breast tumor cell growth by conjugated linoleic acid via inhibition of 5-lipoxygenase activating protein. Biochim Biophys Acta. 2005; 1736:244-50. https://doi.org/10.1016/j. bbalip.2005.08.015.

34. Jiang WG, Douglas-Jones AG, Mansel RE. Aberrant expression of 5-lipoxygenase-activating protein (5-LOXAP) has prognostic and survival significance in patients with breast cancer. Prostaglandins Leukot Essent Fatty Acids. 2006; 74:125-34. https://doi.org/10.1016/j. plefa.2005.10.005. 
35. Peters-Golden M, Brock TG. 5-lipoxygenase and FLAP. Prostaglandins Leukot Essent Fatty Acids. 2003; 69:99-109.

36. Serio KJ, Reddy KV, Bigby TD. Lipopolysaccharide induces 5-lipoxygenase-activating protein gene expression in THP-1 cells via a NF-kappaB and C/EBP-mediated mechanism. Am J Physiol Cell Physiol. 2005; 288:C112533. https://doi.org/10.1152/ajpcell.00296.2004.

37. Reddy KV, Serio KJ, Hodulik CR, Bigby TD. 5-lipoxygenase-activating protein gene expression. Key role of CCAAT/enhancer-binding proteins $(\mathrm{C} / \mathrm{EBP})$ in constitutive and tumor necrosis factor (TNF) alpha-induced expression in THP-1 cells. J Biol Chem. 2003; 278:13810 8. https://doi.org/10.1074/jbc.M211102200.

38. Cowburn AS, Holgate ST, Sampson AP. IL-5 increases expression of 5-lipoxygenase-activating protein and translocates 5-lipoxygenase to the nucleus in human blood eosinophils. J Immunol. 1999; 163:456-65.

39. Gonsalves CS, Kalra VK. Hypoxia-mediated expression of 5-lipoxygenase-activating protein involves HIF-1alpha and NF-kappaB and microRNAs 135a and 199a-5p. J Immunol. 2010; 184:3878-88. https://doi.org/10.4049/ jimmunol.0902594.

40. Gyorffy B, Surowiak P, Budczies J, Lanczky A. Online survival analysis software to assess the prognostic value of biomarkers using transcriptomic data in non-small-cell lung cancer. PLoS One. 2013; 8:e82241. https://doi.org/10.1371/ journal.pone.0082241.

41. Maier T, Guell M, Serrano L. Correlation of mRNA and protein in complex biological samples. FEBS Lett. 2009; 583:3966-73. https://doi.org/10.1016/j.febslet.2009.10.036.

42. Bartel DP. MicroRNAs: target recognition and regulatory functions. Cell. 2009; 136:215-33. https://doi.org/10.1016/j. cell.2009.01.002.

43. Taganov KD, Boldin MP, Chang KJ, Baltimore D. NF-kappaB-dependent induction of microRNA miR-146, an inhibitor targeted to signaling proteins of innate immune responses. Proc Natl Acad Sci U S A. 2006; 103:12481-6. https://doi.org/10.1073/pnas.0605298103.

44. Chen W, Li Z, Bai L, Lin Y. NF-kappaB in lung cancer, a carcinogenesis mediator and a prevention and therapy target. Front Biosci (Landmark Ed). 2011; 16:1172-85.

45. Goulet JL, Snouwaert JN, Latour AM, Coffman TM, Koller $\mathrm{BH}$. Altered inflammatory responses in leukotriene-deficient mice. Proc Natl Acad Sci U S A. 1994; 91:12852-6.

46. Guo Y, Wang X, Zhang X, Sun Z, Chen X. Ethanol promotes chemically induced oral cancer in mice through activation of the 5-lipoxygenase pathway of arachidonic acid metabolism. Cancer Prev Res (Phila). 2011; 4:186372. https://doi.org/10.1158/1940-6207.CAPR-11-0206.

47. Duffield-Lillico AJ, Boyle JO, Zhou XK, Ghosh A, Butala GS, Subbaramaiah K, Newman RA, Morrow JD, Milne GL, Dannenberg AJ. Levels of prostaglandin E metabolite and leukotriene $\mathrm{E}(4)$ are increased in the urine of smokers: evidence that celecoxib shunts arachidonic acid into the 5-lipoxygenase pathway. Cancer Prev Res (Phila). 2009; 2:322-9. https://doi.org/10.1158/1940-6207. CAPR-09-0005.

48. Park SW, Heo DS, Sung MW. The shunting of arachidonic acid metabolism to 5-lipoxygenase and cytochrome p450 epoxygenase antagonizes the anti-cancer effect of cyclooxygenase-2 inhibition in head and neck cancer cells. Cell Oncol (Dordr). 2012; 35:1-8. https://doi.org/10.1007/ s13402-011-0051-7.

49. Ye YN, Wu WK, Shin VY, Bruce IC, Wong BC, Cho $\mathrm{CH}$. Dual inhibition of 5-LOX and COX-2 suppresses colon cancer formation promoted by cigarette smoke. Carcinogenesis. 2005; 26:827-34. https://doi.org/10.1093/ carcin/bgi012.

50. Saba R, Sorensen DL, Booth SA. MicroRNA-146a: a dominant, negative regulator of the innate immune response. Front Immunol. 2014; 5:578. https://doi. org/10.3389/fimmu.2014.00578.

51. Labbaye C, Testa U. The emerging role of MIR-146A in the control of hematopoiesis, immune function and cancer. J Hematol Oncol. 2012; 5:13. https://doi. org/10.1186/1756-8722-5-13.

52. Hou J, Wang P, Lin L, Liu X, Ma F, An H, Wang Z, Cao X. MicroRNA-146a feedback inhibits RIG-I-dependent Type I IFN production in macrophages by targeting TRAF6, IRAK1, and IRAK2. J Immunol. 2009; 183:2150-8. https:// doi.org/10.4049/jimmunol.0900707.

53. Bhaumik D, Scott GK, Schokrpur S, Patil CK, Campisi J, Benz CC. Expression of microRNA-146 suppresses NF-kappaB activity with reduction of metastatic potential in breast cancer cells. Oncogene. 2008; 27:5643-7. https:// doi.org/10.1038/onc.2008.171.

54. Nahid MA, Pauley KM, Satoh M, Chan EK. miR-146a is critical for endotoxin-induced tolerance: implication in innate immunity. J Biol Chem. 2009; 284:34590-9. https:// doi.org/10.1074/jbc.M109.056317.

55. Zhao JL, Rao DS, Boldin MP, Taganov KD, O'Connell RM, Baltimore D. NF-kappaB dysregulation in microRNA146a-deficient mice drives the development of myeloid malignancies. Proc Natl Acad Sci U S A. 2011; 108:9184-9. https://doi.org/10.1073/pnas.1105398108.

56. Sonoshita M, Takaku K, Sasaki N, Sugimoto Y, Ushikubi F, Narumiya S, Oshima M, Taketo MM. Acceleration of intestinal polyposis through prostaglandin receptor EP2 in Apc(Delta 716) knockout mice. Nat Med. 2001; 7:1048-51. https://doi.org/10.1038/nm0901-1048.

57. Huang M, Stolina M, Sharma S, Mao JT, Zhu L, Miller PW, Wollman J, Herschman H, Dubinett SM. Non-small cell lung cancer cyclooxygenase-2-dependent regulation of cytokine balance in lymphocytes and macrophages: up-regulation of interleukin 10 and down-regulation of interleukin 12 production. Cancer Res. 1998; 58:1208-16.

58. Chen G, Umelo IA, Lv S, Teugels E, Fostier K, Kronenberger P, Dewaele A, Sadones J, Geers C, De Greve J. miR-146a 
inhibits cell growth, cell migration and induces apoptosis in non-small cell lung cancer cells. PLoS One. 2013; 8:e60317. https://doi.org/10.1371/journal.pone.0060317.

59. Li YL, Wang J, Zhang CY, Shen YQ, Wang HM, Ding L, Gu YC, Lou JT, Zhao XT, Ma ZL, Jin YX. MiR-146a-5p inhibits cell proliferation and cell cycle progression in NSCLC cell lines by targeting CCND1 and CCND2. Oncotarget. 2016; 7:59287-98. https://doi.org/10.18632/oncotarget.11040.

60. Jiang S, Zhang S, Langenfeld J, Lo SC, Rogers MB. Mycoplasma infection transforms normal lung cells and induces bone morphogenetic protein 2 expression by post-transcriptional mechanisms. J Cell Biochem. 2008; 104:580-94. https://doi.org/10.1002/jcb.21647.

61. Gerritsen ME, Nganele DM, Rodrigues AM. Calcium ionophore (A23187)- and arachidonic acid-stimulated prostaglandin release from microvascular endothelial cells: effects of calcium antagonists and calmodulin inhibitors. J Pharmacol Exp Ther. 1987; 240:837-46.

62. Li LC, Dahiya R. MethPrimer: designing primers for methylation PCRs. Bioinformatics. 2002; 18:1427-31. 